\title{
WestVirginiaUniversity
}

THE RESEARCH REPOSITORY @ WVU

Graduate Theses, Dissertations, and Problem Reports

2001

\section{Prevalence of Campylobacter in a turkey production facility}

Aaron Shawn Kiess

West Virginia University

Follow this and additional works at: https://researchrepository.wvu.edu/etd

\section{Recommended Citation}

Kiess, Aaron Shawn, "Prevalence of Campylobacter in a turkey production facility" (2001). Graduate Theses, Dissertations, and Problem Reports. 1314.

https://researchrepository.wvu.edu/etd/1314

This Thesis is protected by copyright and/or related rights. It has been brought to you by the The Research Repository @ WVU with permission from the rights-holder(s). You are free to use this Thesis in any way that is permitted by the copyright and related rights legislation that applies to your use. For other uses you must obtain permission from the rights-holder(s) directly, unless additional rights are indicated by a Creative Commons license in the record and/ or on the work itself. This Thesis has been accepted for inclusion in WVU Graduate Theses, Dissertations, and Problem Reports collection by an authorized administrator of The Research Repository @ WVU. For more information, please contact researchrepository@mail.wvu.edu. 


\title{
Prevalence of Campylobacter in a Turkey Production Facility
}

\author{
Aaron S. Kiess \\ Thesis submitted to the \\ Davis College of Agriculture, Forestry, and Consumer Sciences \\ At West Virginia University \\ In partial fulfillment of the requirements for the degree of
}

\author{
Master of Science \\ in \\ Animal and Veterinary Sciences \\ P. Brett Kenney, Ph.D., Chair \\ Gary K. Bissonnette, Ph.D. \\ Ronald A. Peterson, Ph.D.
}

Division of Animal and Veterinary Sciences

\author{
Morgantown, West Virginia \\ 2001
}

Keywords: turkeys, colonization rate, Campylobacter, campylobacteriosis, preharvest 


\section{ABSTRACT \\ Prevalence of Campylobacter in a Turkey Production Facility}

Aaron Shawn Kiess

Frequency of detection was monitored in three flocks of turkeys from May, 2000 to March 2001. The effect of time was considered for hens in flocks 1 and 2, and the effect of time, gender, and litter (fresh or used) was determined for flock 3. Poults, poultbox liners, waterers, and fecal droppings were monitered throughout production for the presence of Campylobacter using Campy-Cefex agar incubated at $42{ }^{\circ} \mathrm{C}$ under microaerophilic conditions $\left(85 \% \mathrm{~N}_{2}, 10 \% \mathrm{CO}_{2}\right.$, and $\left.5 \% \mathrm{O}_{2}\right)$. Peak colonization occurred near 3 weeks of production. Frequency of Campylobacter isolation from bird sources paralleled isolation from waterers. Frequency of detection from birds placed originally on used litter was significantly lower than detection from birds placed originally on fresh litter ( 2 v. $58 \%)$. Gender did not affect rate of detection. Controls to minimize peak colonization at 3 weeks and appropriate litter management are opportunities to reduce the level of this organism in turkeys. 


\section{Acknowledgments}

First I wish to thank Dr. P. Brett Kenney for his support throughout the difficult times of my tenure as his graduate student. Without his dedication to me through the difficult times of writing my goal could not have been met. I would also like to thank the other members of my committee Dr. Gary Bissonnette and Dr. Ronald Peterson for their support and guidance. Special thanks to my colleagues Mr. Rodney Kiser, Mr. Josh Mathias, Ms. Susan Slider, Ms. Callee McConnell and Ms. Elise Morton without their

help the work could not have been completed. Finally I wish to thank my parents without their love and reassurance none of this could have been accomplished. 


\section{Table of Contents}

PAGE

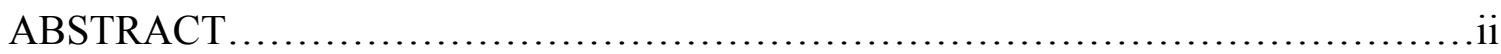

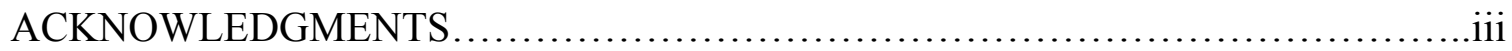

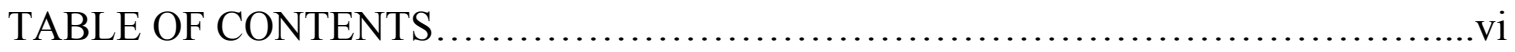

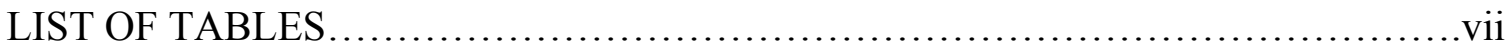

LIST OF FIGURES................................................................ii

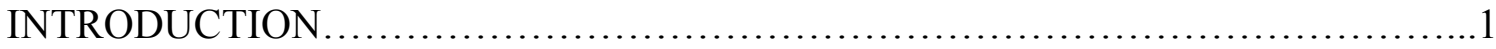

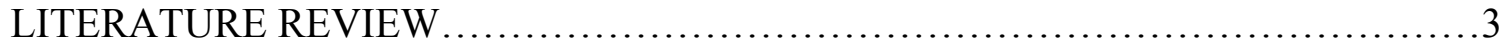

Characteristics of the Organism................................................

Turkey Production System........................................................

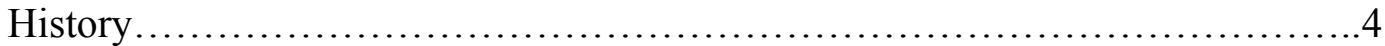

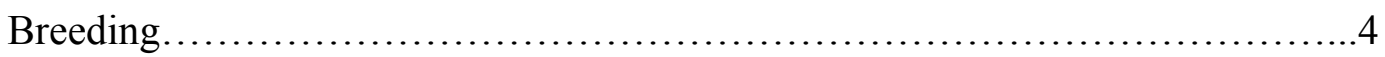

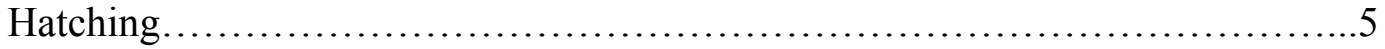

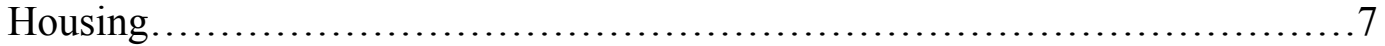

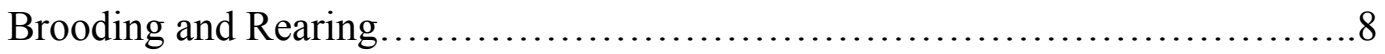

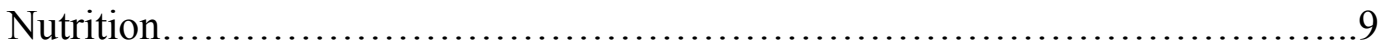

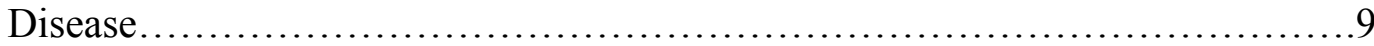

Flock Management.................................................... 10

Prevalence of Campylobacter in turkeys and their Products.........................10

Preharvest (Production) factors affecting the frequency of Campylobacter ............18

Isolation and Detection of Campylobacter.....................................23

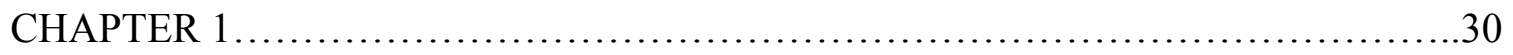

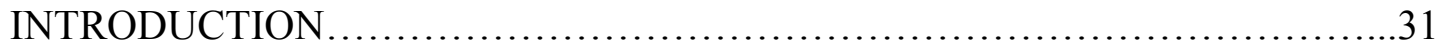

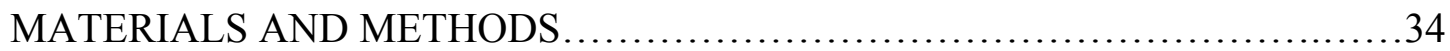


Placement.......................................................... 34

Sample Collection and Transport....................................... 35

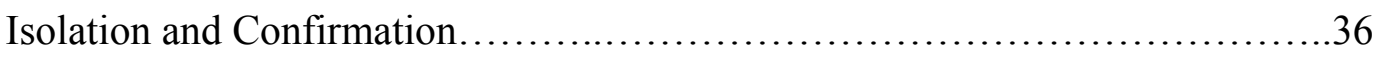

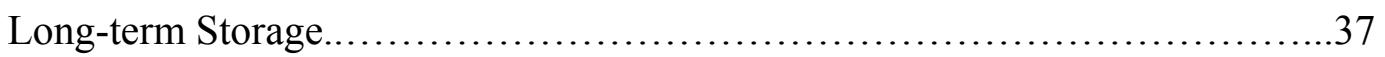

Statistical Analysis....................................................... 37

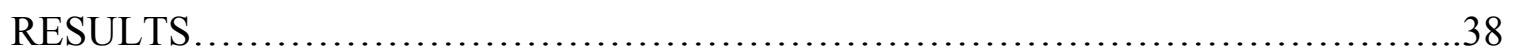

Six-week Production Study........................................... 38

Twenty-week Production Study ......................................... 39

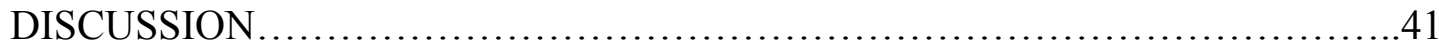

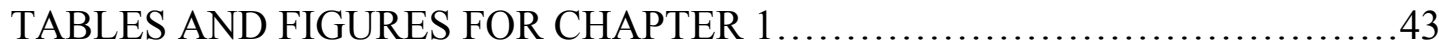

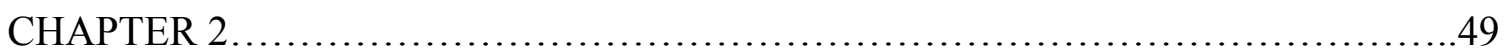

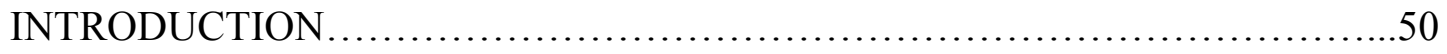

MATERIALS AND METHODS............................................. 52

Resuscitation of Environmental Samples...............................52

Sample Preparation.....................................................52

Polymerase Chain Reaction (PCR) ..................................53

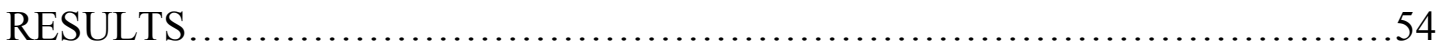

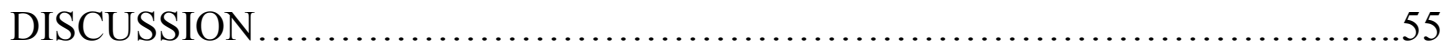

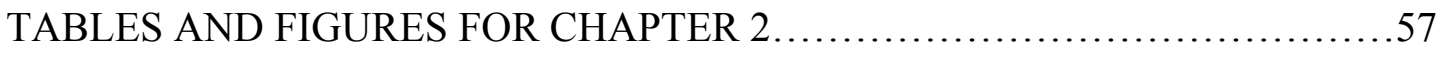

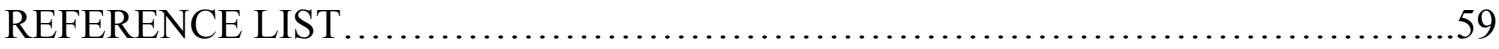

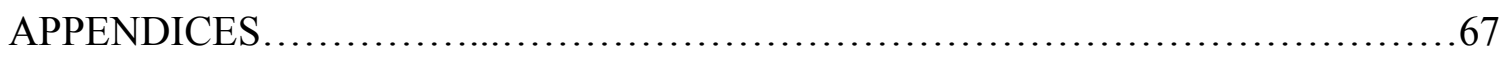

Pen assignment for Flock 3, 20-wk Trial.................................68

Campy-Cefex Agar...................................................69

Campylobacter Enrichment Broth....................................... 70

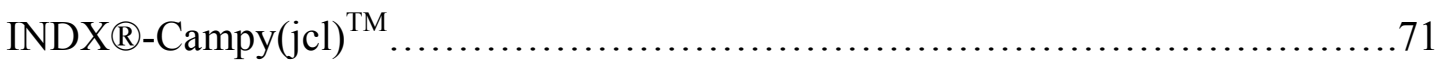


Protect $^{\mathrm{TM}}$ Bacterial Preservers............................................ 74

Wang's Transport Storage Media........................................... 75

PCR Reaction Premix................................................... 76

SAS program for analysis of Six-wk Data................................... 77

SAS program for analysis of Twenty-wk Data................................ 79

Effect of gender on frequency of Campylobacter isolation from turkeys.............81

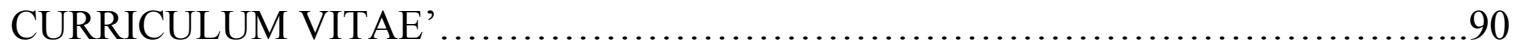




\section{List of Tables}

CHAPTER $1 . \quad$ PAGE

Table 1. Samples collected from two 6 -wk studies.................................44

Table 2. Samples collected from 20 -wk study ....................................... 45

APPENDICES

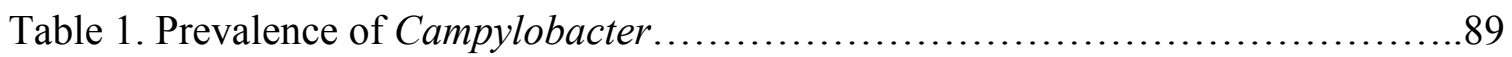




\section{List of Figures}

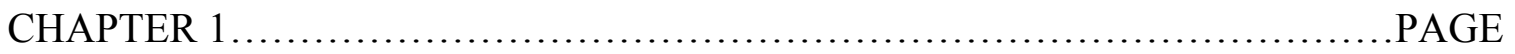

Figure 1. Pen Configuration for 6 -wk Trials..................................47

Figure 2. Housing Design for 20 -wk Trial...................................48

CHAPTER 2

Figure 1. Unweighted pair-grouped method with Arithmetic means Analysis............58 


\section{Introduction:}

Campylobacter, a pathogenic organism, is a food borne health concern. In the past, Campylobacter, formerly known, as Vibrio was only acknowledged as an organism responsible for causing stillborn births in cattle and sheep. This limited understanding is due to the fact that the organism is very fragile and requires specific environmental conditions to exist. It was not until the 1970's that scientists began understanding Campylobacter's contribution to food borne illness. Campylobacter is now a leading cause of food borne illness in the United States (U.S. Food and Drug Administration, 1999). Each year it is estimated that over 2 million individuals are infected by this pathogen, resulting in approximately 500 deaths (Center for Disease Control and Prevention, 2000). This rate of infection has made Campylobacter even more prevalent than some more recognized pathogens like Salmonella, Shigella and E.coli O157:H7 (U.S. Food and Drug Administration, 1999). Campylobacter infects the gastrointestinal tracts of household pets (cats and dogs), domestic livestock (cattle, sheep, swine and poultry), as well as humans. Exposure to less than 500 organisms has the potential to cause the disease, campylobacteriosis. Infection occurs within 2 to 10 days after exposure to the organism. Symptoms include fever, headaches, muscle pain, nausea and bloody diarrhea (Food Safety and Inspection Service, 1999). The severity of these infections, in most cases, is not serious, and symptoms are only experienced for a week.

In a few incidences, the infection can spread to other parts of the body like the vascular or nervous system. Campylobacteriosis can also cause arthritis and Guillan-Barre syndrome (GBS), a disease that affects the nervous system causing paralysis (Patterson, M.F., 1995) 
Campylobacter is transmitted to humans by improper processing, handling and consumption of raw or undercooked food products. The cross contamination of food items like fruits and vegetables used in salads with raw poultry is thought to be a major source of infection. By thoroughly cooking and properly handling the product, infection by this organism can be reduced or stopped (Center for Disease Control and Prevention, 2000). The objectives of this study were to 1). evaluate the frequency of Campylobacter in turkeys and 2). to determine if vertical transmission of the bacteria from the parent to the egg may be a source for contamination of the poults. Since most research in this area of food microbiology has been performed on broilers more information is needed for turkey producers. 


\section{LITERATURE REVIEW}

\section{Characteristics of the Organism}

Organisms in the genus Campylobacter are defined as slender, vibroid, gram-negative cells, 0.2-0.5 $\mu \mathrm{m}$ wide and 0.5-5 $\mu \mathrm{m}$ long (Hensyl, 1994). Campylobacter can also take a rod or spiral shape, where they can measure up to $8 \mu \mathrm{m}$. It is non-spore forming and may take on a coccoid or spherical form in older cultures. When two or more organisms come together, they may appear as S-shaped or gull winged. It is motile and moves in a characteristic corkscrew motion. The motion is possibly due to a single polar flagellum that is attached at either one or both ends of the cell. The flagella can be up to three times as long as the main body of the organism. Campylobacter is microaerophilic requiring less than $5 \% \mathrm{O}_{2}$ to live. In a few strains of Campylobacter, up to $20 \% \mathrm{O}_{2}$ can be tolerated. It is a chemoorganotroph that relies on a respiratory type of metabolism in which amino acids and tricarbocyclic acid cycle intermediates are needed for energy. Carbohydrates are neither fermented nor oxidized by this organism. Some species of Campylobacter can grow under anaerobic conditions. For this to happen, fumarate, formate and fumarate, or $\mathrm{H}_{2}$ and fumarate must be present in the growth media or environment. Serum or blood is not a requirement for growth or when testing for Campylobacter conformation. They are able to reduce nitrates, gelatin is not hydrolyzed and methyl red and Voges-Proskauer tests are negative. No lipase activity can be seen. Oxidase is positive and urease is negative, except for a few strains of $C$. lari. Some species are pathogenic to humans and animals. They are found in the intestinal tracts, reproductive organs and oral cavities of humans and animals (Hensyl, 1994). 


\section{Turkey Production System \\ History}

Over 8000 years ago the first species of fowl (red jungle fowl) was captured and domesticated. The selection process was based on fighting behavior. This selection process was motivated by entertainment value. It was then discovered by Romans, that the fowl offered other characteristics, that were more beneficial to people. The fowl, once domesticated, could be used as a source of meat and eggs that added to the nutrition of the people (Appleby, et al., 1992). The Aztec Indians of Mexico first achieved domestication of the wild turkey. Although the wild turkey was also native to North America, the Native Indians only hunted turkey, and this provided food for consumption and feathers, for clothes and headdresses. The Spanish also domesticated the wild turkey, it was then sent back to their homeland of Spain. In Spain domestication was continued, and turkey was eventually accepted by most of the European countries. By 1573 many other countries like France, Italy and England also adopted the turkey. The first settlers reintroduced the domesticated turkey of the European countries to the Americas. From that time, turkey production has grown into an industry (Moreng, et al., 1985).

The turkey production system is a highly regulated operation. When raising turkeys, many steps are considered so that production will be successful. To achieve the level of production demanded by the industry, special attention is paid to breeding, hatching, housing, brooding and rearing, nutrition, disease and flock management.

\section{Breeding}

In today's turkey production systems, the most prominate breeds used are the large white and large bronze turkeys (Appleby, et al., 1992). To establish a healthy and productive line of turkeys, genetics is the starting point. Economically important traits are governed by a combination of genes. The industry has become indebted to the 
science of quantitative genetics (Austic, et al., 1990). Due to this field of genetics, meat birds have been selected for growth rate, meat yield, ratio of white to dark muscle and rapid feathering. When a turkey is selected to carry one or two of these genes, it becomes a part of the grandparent flock. Then by crossing the grandparents, a parent is made. This turkey then carries genes to produce the meat bird. Scientists have looked for genes that will enhance feed efficiency. Producers want a turkey that has high output to low food intake. This is desirable, since the highest cost to the production system is feed. Further research in the field of genetic engineering, will improve efficiency of production and turkey welfare (Moreng, et al., 1985).

\section{Hatching}

Incubating and hatching turkey eggs are complicated processes, with critical limits that must be monitored thoroughly for maximum hatch to occur. Incubation can occur in two ways. The single-stage method of incubation allows for all the eggs, which are all at the same stage of development, to be set in the incubator at one time. The single stage incubator allows for fine-tuning, of the temperature, humidity and ventilation. Another reason for using this method of incubation is that the hatching cabinet can be thoroughly cleaned after the hatch is finished. On the other hand, multistage incubation allows eggs to be set in the incubator at different times, creating an incubator with eggs at different stages of development resulting in a continuous hatch. In most cases when using this method of incubation, eggs are set on a weekly basis, where one quarter of the incubator is set at a time. Turkey eggs usually incubate for 25 days and then the eggs are set into a hatching box for an additional 3 days so the poults can pip out. During this period of time, much care must be taken to ensure that the correct temperature, humidity and ventilation are maintained. The temperature at which turkey eggs should be incubated is 
around $99.5^{\circ} \mathrm{F}$. A deviation of just 2 to 3 degrees can be problematic. When temperature rises above the optimum temperature the poult may be forced into using its yolk early, therefore dehydration or emaciated poults may hatch. If the temperature is to low, poults may become lazy, fat and pipped or unhatched embryos may result. To prevent these problems from occurring, temperature should be monitored on a consistent basis. If adjustments are needed, they should be done in increments of $0.2^{\circ} \mathrm{F}$. Another area that must be constantly monitored is humidity. If proper humidity is not maintained inside the entire incubator, the hatching embryos can experience a number of defects. When the humidity is too high, the eggs may not lose enough water. This results in poor air cell formation. If the humidity is too low, eggs may lose too much water. If this happens, the embryos may become dehydrated causing poor hatchability. For these problems not to occur, a relative humidity of $83 \%$ is recommended. Proper ventilation is also very important. As the embryos grow within the egg, the need for oxygen increases. When oxygen requirements increase, carbon dioxide levels will also increase. This is why ventilation is so important. With ventilation, the right amount of $\mathrm{O}_{2}$ can be brought in and $\mathrm{CO}_{2}$ removed. There are two systems that can be used to ventilate incubators. The first method is regulated with computer controls linked to the heating and cooling system. The second method is manual. For either method, the need to bring in $\mathrm{O}_{2}$ and exhaust $\mathrm{CO}_{2}$ is the main function. Attention to this critical step in incubation must be taken. With too much ventilation, a decrease in temperature and humidity may occur, whereas without enough ventilation, $\mathrm{CO}_{2}$ can build up resulting in a poor hatch. Following hatching, vaccination, debeaking and declawing may be carried out. 


\section{Housing}

Once poults have hatched, the next need in the production system is housing.

Housing today is not as simple as it was a hundred years ago. The design of today's turkey house is based on production objective and location of the house and it is focused on maximizing growth (Moreng, et al., 1985). In the past minimal housing was needed. This was due to the fact that turkeys were mostly free ranged, meaning they were allowed out of the building into an enclosed area. The house in this system provided protection to the birds from predators at night (Appleby, et al., 1992). Today, turkeys are raised in environmentally controlled buildings. Birds are raised from poults until they are finished. The house provides protection, efficient space, proper lighting, ventilation and heat. Turkeys, used on their genetic predisposition to growth, are raised for specific periods of time in the house. Female turkeys are usually finished by 17 weeks of age and male turkeys are usually finished by 24 weeks (Austic, et al., 1990). All the items mentioned above are all regulated by good management practices. If management is not considered when the house is being designed, it will not be effective. Engineers, when designing a building take great care in deciding how the building should be ventilated, heated, insulated, sanitized, lighted, and plumbed (Austic, et al., 1990). Laborers comfort is also considered. If laborers are not comfortable, birds will suffer. Laborers want to get in and out of the house as quickly as possible, which may result in certain indicators of birds well being overlooked (Appleby, et al., 1992). All of these factors depend on location, climate and space needed by the birds, ensuring the building will produce a profitable end product. 


\section{Brooding and Rearing}

Brooding poults is similar to a nursery period; when poults arrive at the house, strict care must be taken to maintain their health. The first step taken is to ensure that the house has been properly cleaned and sanitized. Once the house has been inspected, the producer will then heat the house. This occurs approximately $12 \mathrm{~h}$ before poults arrive (Moreng, et al., 1985). Turkey poults are raised on the floor of the house; fresh shavings are laid down for the comfort of the poults. Brooding rings are set up to keep the poults in and around the brooder so they will not get too cold. The brooder is a heating device that maintains temperature around $99.5^{\circ} \mathrm{F}$. Waters are adjusted to the correct height or depth to allow for easy access (Austic, et al., 1990). When poults arrive at the house, behavior is observed. Observations will indicate whether poults are getting too hot or cold. The producer will note if the birds are consuming water, turkeys may be hard to start on feed and water. If this occurs, it is not uncommon for the laborers to dip the poults head in the water to familiarize them with it. Feed is not put into the brooding ring for about $4 \mathrm{~h}$ after poults arrive. This practice allows birds to consume some water first in case they are dehydrated from the trip to the house (Moreng, et al., 1985). During brooding, laborers and producers carefully monitor heat, airflow, moisture and space allowed for each poult. Once poults have been monitored for a week within the brooding ring and all poults are eating and drinking, the ring can be taken down and the brooder turned off and raised. More room will be needed for growing poults and this need should be taken care of by building design (Appleby, et al., 1992). Feeders and waters should be placed throughout the house to allow for access. As poults grow, all behavior and areas 
previously mentioned should be continuously monitored. If not watched, bird performance will decrease and so will profit.

\section{Nutrition}

The leading cost to turkey production is feed, thus nutrition is a primary concern to the industry. Energy requirement for turkeys cannot be designed with amino acids, vitamins and minerals alone (Austic, et al., 1990). The major goal of the nutritionist is to design a feeding program that includes all essential ingredients and maximizes muscle growth as economically as possible (Moreng, et al., 1985). Nutritionists have designed feeding programs that maximize growth efficiency of turkeys. As turkeys age, metabolic energy requirements increase. For young poults, requirement for metabolic energy is around 1250 to $1350 \mathrm{kcal}$; whereas older turkeys require 1400 to $1500 \mathrm{kcal}$ of metabolic energy (Austic, et al., 1990). Concurrently, protein requirements decrease with age. Most diets use carbohydrate sources to substitute for protein such as corn or soy. Essential vitamins and minerals increase or decrease with the age of the turkey (BUTA). A well-developed management plan will recognize the turkey requirement and, if a ration is needed for a longer or shorter period of time, adjustments can be made (Appleby, et al., 1992).

\section{Disease}

Diseases are another major concern to the turkey industry. If a disease does become a problem, it could affect the entire flock possibly causing death to all birds. For this reason, all attempts to ensure that diseases do not occur are taken. A disease may be defined as any deviation from the normal state of well being. This deviation could appear as a slight ailment in a single bird or one that endangers the life of the entire flock (Moreng, et al., 1985). Disease agents can be specific pathogens, nutritional deficiency, 
toxic agents or even environmental changes. Diseases that are most common and managed by sanitation practices and vaccination are viruses, bacteria, fungi, protozoan, poisons, and internal and external parasites (Austic, et al., 1990). Methods of disease prevention include vaccination, sanitation, farm security, and the practice of all-in/all-out management. When proper hygiene is practiced and observation of flock health is recorded accurately, disease outbreaks are minimized (Appleby, et al., 1992).

\section{Flock Management}

Management is essential to every area of the system, and if not properly practiced by all personnel, it could cause failure of the entire operation. Moreng (1985) stated " The design of a management program for a poultry flock should be based upon the efficiency of operation necessary to meet the production objectives of the unit. Efficient use of space, equipment, time, and employee's knowledge should combine with many other factors which must be applied toward the production goals of a specific program". Breeding, hatching, housing, rearing and marketing should be considered in development of a management program. When poult comfort, employee welfare, breeding, hatching, disease prevention, and rearing are managed properly, benefits will be realized. If problems are not solved promptly and production is halted, management has failed. The goal of management is efficient and profitable production.

\section{Prevalence of Campylobacter in turkeys and their products}

Over the years, interest in Campylobacter has increased because of increasing links between it and gastroenteritis (Quinones-Ramirez et al., 2000). Poultry, sheep, pigs and cattle, at various levels, carry it. In poultry, a major reservoir for Campylobacter, studies have indicated levels of 8.1 to $100 \%$ (Quinines-Ramirez et al. 2000). Doyle (1984) associated Campylobacter with all parts of the poultry system from live birds to retail 
products. In the live bird, many studies had been carried out to determine if they were a source of contamination. Initially, experiments were designed to see if poultry actually harbored the organism (Campylobacter). Smith and Muldoon (1974) were a few of the first to document the presence of Campylobacter jejuni associated with poultry carcasses. Acuff and coworkers (1982) looked for Campylobacter in turkey eggs, poults and brooding houses. They reported that poults, 15 to 19 days of age, had a frequency of contamination of 16 to $76 \%$ respectively. They also sampled litter, grit, feed and water from within the house. Water and litter were positive for Campylobacter, but grit and feed were not. When fertile eggs and newly hatched poults were sampled, neither harbored Campylobacter. Doyle (1984) investigated the excretion patterns of C. jejuni in individually caged laying hens. He found that $8.1 \%$ of the laying hens were chronic carries of the bacteria. He also found that an increase of $25 \%$ in the shedding of Campylobacter occurred during the months of October and late April through early May. Doyle (1984) concluded that Campylobacter could not penetrate the egg, but when eggs had fecal material on them, it was possible to isolate Campylobacter. Poultry provide an optimum environment for Campylobacter, but the bacterium does not cause disease in the host.

Stern and coworkers (1988) investigated this commensal relationship between Campylobacter and poultry. They evaluated colonization dosage, age of the host and strain variability relative to cecal colonization influence of competitive exclusion (CE). All chicks challenged with $10^{5} \mathrm{cfu} / \mathrm{chick}$ were consistently colonized. When six different strains of C. jejuni were used as a challenge, four showed permanent attachment properties. One other strain did show consistent colonization, but it was by oral-fecal 
passage among the flock. When birds were given competitive exclusion cultures from mature adult microflora, no difference was seen in the colonization rate of Campylobacter in the birds. For birds treated with CE cultures, 81 of 84 were colonized and 45 of 46 of the control birds were also colonized.

Kwiateck and coworkers (1990) looked at the presence of Campylobacter on poultry and slaughter animals in Poland. They sampled chickens, ducks, geese, turkeys, pigs and cattle. Out of 839 samples, $80.3 \%$ of chicken, $48 \%$ of duck, $38 \%$ of geese, $3 \%$ of turkey, $2.9 \%$ of porcine and $0.9 \%$ of bovine samples taken were positive for Campylobacter. Jones (1991) evaluated the rate of $C$. jejuni contamination at various points in broiler production and processing systems. He indicated that feed mills, hatcheries, insects, and mice were all negative for $C$. jejuni. Insects were externally cleaned with ethanol, so the negative counts were all based on internal colonization of insects, nonetheless external transmission may be possible. In this experiment the actual source for contamination could not be determined. Broilers entering the slaughter facility had cloacal swabs taken; of those samples, $20 \%$ were positive for $C$. jejuni. It was also found that $52 \%$ of carcasses, post chilling were positive. Whole broiler carcasses, once processed, were also contaminated with $C$. jejuni at a frequency of $31.6 \%$. Grados and coworkers (1988) studied free-range chickens. C. jejuni was present in birds that had access to a backyard lot. Adekeye and coworkers (1989) observed that Campylobacter acts as if it was part of the normal flora. They found that in intensive management and free-range management systems Campylobacter colonization was almost identical. Pearson and coworkers (1993) investigated an outbreak of $C$. jejuni infections in Bournemouth, United Kingdom. The outbreak was associated with a catering college that was supplied with chicken from 
a single wholesaler. Pearson and colleagues traced the $C$. jejuni back to a farm that had a contaminated water supply.

Stern and coworkers (1994) examined the possibility that when chicks are challenged with viable but non-culturable (VBNC) suspensions of Campylobacter, colonization may occur. They indicated that some chicks challenged by oral gavages of VBNC suspensions became colonized. Confirmation was done by two laboratories that used heat-stable and heat-labile serotyping schemes. Stern and coworkers (1995) studied the role of transport and holding on Campylobacter colonization rates. They found that 9 of 10 farms sampled had broilers contaminated with Campylobacter. When birds were examined before and after transport and holding, a higher level of contamination occurred after transport and holding. To reconfirm this finding, five additional farms, and 200, six-week old chickens were studied. Before transport, $12 \%$ of birds harbored an average of $2.71 \log _{10} \mathrm{cfu} /$ carcasses. After transport, this level of contamination increased to $5.15 \log _{10} \mathrm{cfu} /$ carcass in $56 \%$ of the birds sampled. On two Dutch broiler farms, Jacobs-Reitsma and coworkers (1994) found that $100 \%$ of the samples collected were positive for Campylobacter. Neill and coworkers (1984) found that 10 of 12 flocks sampled did not produce Campylobacter positive samples when the chicks were at 2weeks of age. As the birds aged, the flock became colonized, but the source of colonization could not be found. Aho and Hirn (1988) reported that C. jejuni colonization was very low, around 1.7\%, at 4-5 weeks of age. At slaughter (6-7 weeks), the frequency of $C$. jejuni colonization had increased significantly to around 24\%. With levels as high or higher than seen by Aho and Hirn (1988) the possibility for contamination during processing is high. Grant and coworkers (1980) examined broiler 
chickens to see if they presented a potential source of infection with Campylobacter. In 46 broiler chickens, $38(83 \%)$ harbored Campylobacter at an average level of $4.4 \times 10^{6}$ $\mathrm{cfu} / \mathrm{g}$ of feces. The organism survived in feces for $96 \mathrm{~h}$ at $4^{\circ} \mathrm{C}$. This study showed that the potential for contamination in the processing plant is high.

Campylobacter in processing plants has been studied extensively. Leuchtefeld and Wang (1981) studied the patterns of Campylobacter contamination in a turkey processing plant. In this study, 600 cecal and fecal droppings were collected over a 1-year period, and many samples were positive for Campylobacter. Thirty-three, fresh-dressed carcasses were examined before chilling in chlorinated ice water. From those samples, $94 \%$ were positive, and after overnight soaking, $34 \%$ of 83 carcasses were still contaminated. These investigators sampled gutters, chutes, conveyor belts and water treatment lagoons, and positive samples were collected from all sources while the plant was in operation. Four days after shutting the plant down during the winter all samples taken were negative.

Svedhem and coworkers (1981) looked at the occurrence of C. jejuni in fresh foods as well as the survival of the bacteria under different conditions. They found that C. jejuni survived on food items at $4^{\circ} \mathrm{C}$ for a week and at $-20^{\circ} \mathrm{C}$ for up to 3 months. They indicated that by cooking food for $15 \mathrm{~min}$ at $60^{\circ} \mathrm{C}$ was enough to destroy $C$. jejuni. Park and coworkers (1981) examined the incidence of $C$. jejuni in fresh, eviscerated whole chickens. C. jejuni was recovered at a frequency rate of 62 and $42 \%$ from Ontario and Ohio samples respectively. In Sydney, Australia, Shanker and coworkers (1982) found C. jejuni from 18 of 40 processed carcasses and 134 of 327 cloacal swabs. Eighty two 
percent of chicken and $98 \%$ of human isolates from the same area were identical biotypes.

Kramer and coworkers (2000) applied an epidemiological typing strategy to analysis of fresh meat and poultry fecal samples, and to human isolates from campylobacteriosis cases. All samples and isolates were from the same geographical area and they were collected within the same time frame. Campylobacter spp. were isolated from $73.2 \%$ of 489 samples. Frequency of isolation was highest for chickens at a rate of $83.3 \%$, followed by lamb at $72.9 \%$, pig at $71.7 \%$ and beef livers at $54.2 \%$. For human cases, $89.3 \%$ were C. jejuni and $10.7 \%$ C. coli. Only $30 \%$ of the positive isolates collected from each species were multiple strains, reinforcing the fact that more than one isolate should be selected from each sample.

Barot and coworkers (1983) looked for the location of C. jejuni on chicken livers. They found that of 117 livers sampled from New York retail outlets, 56 were positive for C. jejuni. Thirty-six of the livers showed surface contamination, and two had C. jejuni contamination in the tissue. This contamination was most likely due to unhygienic handling of the offal. Oosterom (1983) evaluated the occurrence of C. jejuni contamination during poultry processing in the Netherlands. Birds, equipment, workers hands and air were determined to be sources for Campylobacter contamination. Intestinal contamination in the birds was found as high as $7 \log _{10} \mathrm{cfu} / \mathrm{gram}$. Scalding reduced $C$. jejuni levels, but levels increased during defeathering and evisceration. Carcasses and livers were contaminated at a frequency of 50 to $75 \%$, respectively. Wempe and coworkers (1983) studied the prevalence of $C$. jejuni at different stages of slaughter in two California chicken processing plants. They found that C. jejuni was 
isolated from $68 \%$ of ready-to-eat products. Sixty to $100 \%$ of cecal and fecal samples had levels of $C$. jejuni as high as $10^{6} \mathrm{cfu} / \mathrm{g}$ when entering the slaughterhouse. This study showed that fecal and cecal contamination of carcasses is possible during the slaughtering process. Harris and coworkers (1986) investigated prevalence of $C$. jejuni/coli $(C . j / c)$ in fresh meats available to the consumers in King County, Washington. A total of 297 samples were collected from a poultry processing plant. From those samples, $56.6 \%$ were positive for C. jejuni/coli. When 862 retail chickens were sampled, $23.1 \%$ were positive and $17.2 \%$ of 29 retail, game hens were also positive. In turkey, pork and beef sampled, C. jejuni and C. coli were not frequently isolated.

Berrang and coworkers (2000) examined levels of Campylobacter associated with broiler chickens entering the processing plant. Campylobacter populations $\left(\log _{10} \mathrm{CFU} / \mathrm{g}\right)$ were 5.4 on feathers, 3.8 on skin, 4.7 in the crop, 7.3 in the ceca, and 7.2 in the colon. Juven and Rogol (1986), looked at the incidence of Campylobacter in chickens at the presalt immersion stage in a kosher processing plant in Israel. For carcasses sampled before immersion, $85 \%$ were contaminated with Campylobacter. After immersion, the frequency of detection (85\%) did not change. These data suggest that salt-water is not an effective way to remove Campylobacter from carcasses. In 1983, Kinde and coworkers estimated the prevalence of $C$. jejuni in chicken wings sold at supermarkets in California. C. jejuni was found in $82.9 \%$ of 94 wing packages. However, after a few days at the supermarket, only $15.5 \%$ of 45 packages were positive. Another study in 1994 by Flynn and coworkers looked at the prevalence of Campylobacter spp. in retail chicken wings in Northern Ireland. They sampled 153 chicken wings that were purchased from retail outlets over a 10 -wk period. For these samples, $64.7 \%$ were contaminated with 
Campylobacter spp. Confirmation was performed with the API-Campy Identification system for Campylobacter.

Acuff and coworkers (1986) evaluated the effects of roasting, braising, stewing, and microwaving on contamination of turkey thighs. Effects of various utensil and handwashing procedures on the survival of $C$. jejuni were also evaluated. Roasting, braising and stewing were all effective in decontaminating turkey thighs of $C j e j u n i$.

Microwaving was most successful when a thermometer was used to evaluate internal temperature. Manually washing utensils with detergent and water was sufficient to remove Campylobacter jejuni, except on wooden cutting boards where dishwashers were needed for proper sterilization. Quinones-Ramirez and coworkers (2000) examined the contamination of $C$. jejuni on poultry that was available to consumers on street stands, the most common for eating in Mexico City. Out of 100 samples from 3 locations, 600 isolates were grown. Of the 600 isolates, 121 were positive. Fifty-one samples were $C$. jejuni, 21 were $C$. coli and 49 were other species. Twenty-seven positive isolates were taken from one stand. Previously cooked poultry had been placed under raw chicken during roasting, allowing cross-contamination to occur.

In 1983, Hopkins and Scott investigated an outbreak of Campylobacter in Colorado. This outbreak was suspected to be due to the mishandling of raw chicken. In ten cases, interviews were conducted on infected persons as well as the family members who were not infected. Nine of 10 infected individuals had handled raw chicken before the onset of symptoms. They concluded that handling raw chicken was more of a risk than the consumption of cooked chicken. In another study, Lammereding and coworkers (1988) developed a national monitoring program in Canada that provided information on the 
status of thermophilic Campylobacter in food animals at the slaughterhouse level.

Thermophilic Campylobacter was isolated from $16.9 \%$ of pork, $22.6 \%$ of beef, and

$43.1 \%$ of veal samples. Campylobacter was isolated from 73.7 and $38.2 \%$ of turkey and chicken samples, respectively.

\section{Preharvest (Production) factors affecting the frequency of Campylobacter}

Poultry is a major reservoir of Campylobacter and the high frequency of Campylobacter occurrence in poultry has also been implicated as a predisposing factor for gastroenteritis in humans. Due to its prevalence, elimination of the pathogen has been the focus of recent research. To eliminate Campylobacter from poultry, a logical step is to identify factors that influence the frequency of Campylobacter in the live bird. Doyle and Roman (1981) looked at the effect that temperature and $\mathrm{pH}$ would have on Campylobacter growth. They indicated that an optimum temperature for Campylobacter was in the range of 42 to $45^{\circ} \mathrm{C}$ and that Campylobacter could grow in a pH range of 5.5 to 8.0. Jones and coworkers (1993) studied the effect of temperature, microaerophilic conditions and air on Campylobacter growth. Optimum growth occurred around $42^{\circ} \mathrm{C}$, but growth was seen at $37^{\circ} \mathrm{C}$ and as low as $4^{\circ} \mathrm{C}$. After $2-3$ days in air, sub cultures could change to aerobic metabolism and grow without microaerophilic conditions. Changes in morphology and outer-membrane proteins were seen, but serotyping reactions were not changed when identifying the organism.

Season affects carriage rate of Campylobacter in poultry. Jacobs-Reitsma and colleagues (1994) investigated risk factors for Campylobacter colonization in Dutch broiler flocks. Of 187 broiler flocks 82\% (153) were contaminated with Campylobacter. Colonization rate varied with season; June through September had the highest rates of 
colonization and March had the lowest colonization rate. In this seasonal study, slaughter house and husbandry practices correlated to Campylobacter contamination, but broiler line and age and geographical location did not affect colonization rate. Stern and coworkers (1995) examined seasonal influence on colonization of broilers with Campylobacter. The lowest levels of Campylobacter were detected in the spring. In the summer and fall, levels were at their highest level. Willis and Murray (1997) determined that the highest number of Campylobacter on carcasses was from May to October. The lowest levels were detected in December and January. These findings support the fact that seasonality influences the detectability of Campylobacter in market broilers.

Other risk factors are associated with the frequency of Campylobacter colonization of poultry. Humphrey and coworkers (1993) conducted a longitudinal study that lasted approximately 12 months and examined the Campylobacter status of broiler flocks. Ceca of up to 100 birds per flock were examined at slaughter. This sampling rate allowed for a study for a variety of environmental and production factors. They determined that bird colonization were not associated with water or the floor structures used in the house; also, no seasonal variation was seen in carriage rate. They indicated that dipping boots prior to entering a house helped to reduce or even eliminate $C$. jejuni in samples collected from the house.

Smith and Fratamico (1995) reviewed factors that were involved in the emergence/recognition and persistence of several bacterial, parasitic, viral and viral-like agents that are associated with food-borne outbreaks. Relative to Campylobacter, they stated that increased emergence or recognition is related to 1) increased awareness of Campylobacter as a food-borne pathogen and 2) the development of better selective 
media for stool and food samples. Relative to factors contributing to the persistence of the pathogen, they implicated raw milk, untreated water, poultry consumption, contact with farm animals and pets, contamination of food by food handlers, and concentration of chickens, pigs and cattle in production systems.

Jacobs-Reitsma and coworkers (1995) conducted a longitudinal study of Campylobacter in broiler flocks and associated environmental sources at two Dutch poultry farms. They determined that the hatchery, water, feed, and fresh litter were not sources of contamination. Darkling beetles carried the same serotype of Campylobacter as the broilers thus acting as a vector for horizontal transmission. In 1996, Cawthraw and coworkers examined the mechanism by which Campylobacter spread through large broiler flocks. They indicated that a dose of $40 \mathrm{cfu} / \mathrm{gram}$ was large enough to maximize colonization in poultry. Van de Giessen and colleagues (1996) identified risk factors as well as risk-reducing measures for Campylobacter infection in Dutch broiler flocks. Risk factors were boots, hand washing, foot baths, improper cleaning with detergents and failure to clean the yard between flocks. Animals and ground water used for cleaning were sources of flock infections.

Transportation contributes to Campylobacter contamination of poultry. Stern and colleagues (1995) investigated the role of transport from the farm to the processing facility in Campylobacter colonization of chickens and contamination of carcasses. Stern indicated that the level of Campylobacter before transport was around $5.44 \log _{10} \mathrm{cfu} / \mathrm{g}$ of cecal matter. After transport and a holding for 16 to $18 \mathrm{~h}$, counts increased to $6.15 \log _{10}$ cfu/g of cecal matter. Achen and coworkers (1998) studied time of onset and duration of C. jejuni shedding and observed that peak excretion of Campylobacter occurred 13-19 
days post inoculation. By market age, $37.5 \%$ of the birds were shedding $C$. jejuni and $12.5 \%$ were chronic carriers. Lindblom and coworkers (1986) examined the natural colonization of chickens by $C$. jejuni during commercial breeding and rearing. No $C$. jejuni was found in newly hatched chicken feces. By 5-9 weeks of age, many samples became positive for $C$. jejuni. Once a bird became colonized, it spread rapidly, but the for the rate of transmission was not known. Feed and water were negative, and environmentally protected birds were colonized over time. These authors suggested that transmission was due to flies and other insects within the house.

The pathway whereby poultry become colonized is still an enigma. Many studies have looked at vertical or horizontal transmission as a pathway by which colonization occurs. Shanker and colleagues (1986) evaluated the role of vertical transmission in $C$. jejuni colonization of a broiler flock. They stated that, in 6 breeder flocks supplying eggs, $74 \%$ of the breeders were positive for $C$. jejuni. Out of 187 eggs sampled, only 2 were identified as Campylobacter carriers. When eggs were incubated and/or challenged with Campylobacter isolates, only two were positive. Thus, vertical transmission was not considered a possible route of infection in broilers. Jacobs-Reitsma (1995) investigated the role of breeder flocks in the epidemiology of Campylobacter in poultry production. Campylobacter was isolated from $67 \%$ of the flocks. Campylobacter colonization of breeder flocks suggested a potential role for vertical transmission, but serotype data did not support this link.

Pearson and coworkers (1996) found that out of 12,233 samples collected, $27 \%$ were positive for Campylobacter. When 251 broiler houses were sampled, $35.5 \%$ were Campylobacter positive. Of those positive houses, only $9.2 \%$ had consecutive samples in 
which Campylobacter could be isolated. In sampling two hatcheries, this group found that the first hatchery had $17.6 \%$ Campylobacter positive samples. In the second hatchery, $42.9 \%$ of the samples were positive. These data support the idea that vertical transmission is a way whereby Campylobacter colonizes chicks.

In 1992, van de Giessen and colleagues used the Penner serotyping and DNA-typing systems to assess roles of vertical and horizontal transmission in C. jejuni infection of poultry flocks. Samples were collected from two broiler houses and the first house had strains of $C$. jejuni that could not be isolated from subsequent flocks. The second house had identical strains of $C$. jejuni isolated from subsequent flocks. In this study, horizontal transmission was suspected to be the major contributor to colonization of poultry flocks. Shanker and colleagues (1990) provided information on horizontal transmission. $C$. jejuni was investigated in Campylobacter-free broiler chickens. When chicks were orally challenged with the organism, $64 \%$ were positive for Campylobacter within 3 days and $89 \%$ were positive by day 7 . When chicks were exposed to contaminated water or seeder chicks, colonization occurred within 2-7 days. When all chicks were removed from the house and environmental samples collected, the house was negative by day 3 . Colonization of 1-day old chicks was not affected when adult cecal microbiota was introduced.

Due to the many opportunities for Campylobacter to colonize poultry, scientists are looking for ways to reduce the frequency of positive birds entering the processing plant. Stern and coworkers (1994) looked at alternative sources of flora antagonistic to $C$. jejuni. Mucosal competitive exclusion flora (MCE) was given to chicks. Forty-eight hours later, chicks were challenged with $C$.jejuni to examine colonization characteristics. 
Exposure to MCE reduced the level of Campylobacter that colonized the chick, but after the MCE was stopped, its effectiveness was reduced. In 1997, Morishita and colleagues evaluated whether the probiotic effect of Lactobacillus acidophilus and Streptococcus facium would reduce colonization and frequency of fecal shedding of C. jejuni in broilers. Birds given probiotics for 1 to 3 days had a $70 \%$ reduction in the frequency of C. jejuni shedding and a $27 \%$ reduction in jejunal colonization at slaughter compared to control groups. Line and coworkers (1997) evaluated the ability of Saccharomyces boulardii to reduce populations of Salmonella and Campylobacter in broiler chickens subjected to feed withdrawal and transport stress. Yeast did not reduce the frequency of Campylobacter isolation from the ceca; however, Campylobacter populations in the ceca were significantly reduced when the culture was given to a chick that was contaminated with both Campylobacter and Salmonella. Line and colleagues (1998) also studied the potential for using a viable, dried preparation of $S$. boulardii in the feed as a defined culture for controlling colonization of broiler chicks with Salmonella typhimurium and $C$.

jejuni. Salmonella colonization was significantly reduced due to the yeast treatment. Campylobacter colonization on the other hand was not affected by yeast treatment. Bailey and coworkers (1993) evaluated technology that would prevent communal intestinal colonization of chickens by human bacterial enteropathogens. Bailey concluded by indicating that the only method to reduce or eliminate $C$.jejuni at the processing plant is to achieve a bird that is $C$. jejuni free.

\section{Isolation and Detection of Campylobacter}

Campylobacter was not recognized as a food-borne pathogen until the 1970's. This 
was due to its fragile state outside its preferred environment. Over the years much research has been conducted on media that can support growth of Campylobacter spp. Many selective media use antibiotics; enrichment media to recover injured cells have been developed. With the advent of DNA-based technology, new products are being developed that can identify Campylobacter spp. using specific deoxyribonucleic acid (DNA) segments through techniques like polymerase chain reactions (PCR) and pulsed field gel electrophoresis (PFGE). Patton and colleagues (1981) compared (Skirrow's, Butzler's and a modified Butzler's, containing a higher concentration of colistin) for there efficiency in the primary isolation of C. fetus subsp. jejuni. Skirrow's and Butzler's and modified Butzler's media were comparable in their isolation of $C$. fetus subsp. jejuni. Modified Butzler's gave the highest level of isolation, and when combined with Skirrow media, $98 \%$ of the isolates obtained could be detected. Butzler and coworkers (1983) compared new selective medium that consisted of Butzler's medium with the addition of cefoperazone, rifampicin, colistin and amphotericin. They found that out of 3,404 stool samples, C. jejuni was isolated with the same frequency (7-9\%) for both media. However, competing fecal flora were strongly suppressed by the new media. Bolton and colleagues (1983) also compared Skirrow's, Butzler's, Campy-BAP and Preston media for Campylobacter spp. isolation from human, animal and environmental specimens. They indicated that the Butzler medium gave the lowest isolation rate; whereas Preston medium, the most selective medium, gave the highest isolation rate. Again in 1984, Bolton and coworkers compared charcoal, cefazolin, sodium deoxycholate (CCD), a blood-free selective agar, to Preston medium for isolation of $C$. jejuni from human feces. 
Both media resulted in similar isolation rates. CCD was less selective for Campylobacter than Preston media.

Lai-King and colleagues (1985) compared growth of C. coli and C. jejuni in the presence of antibiotics used in selective growth media. C.coli was more susceptible to antibiotics that $C$. jejuni; 1 out of 9 antibiotics did not inhibit $C$. coli. Inhibition of $C$. coli on media developed specifically for Campylobacter spp. confirms that $C$. coli may be underestimated when antibiotics are used in the media. In 1988, Lai-King and colleagues evaluated the ability of $C$. coli to grow on a range of media in use for selective culture of Campylobacter spp. C. coli isolates were inhibited more than C. jejuni on selective media developed by Hutchinson and Bolton. Merino and coworkers (1986) compared seven selective media for isolating C. jejuni; these media were Butzler, Blaser, Skirrow, Preston, Preston Blood free agar, Butzler Virion and modified Preston with amphotericin B. All media isolated a similar number of C. jejuni. The Preston, Campylobacter blood free medium with cefoperazone yielded the highest number of C. jejuni isolates; all others allowed abundant growth of other fecal flora. The presence of this fecal flora made detection of suspect colonies difficult and increased the time spent in reading each plate. Gun-Munro (1987) evaluated six selective isolation media for their ability to support the growth of C. jejuni. Gun-Munro also found that Preston medium, charcoal, cefoperazone, sodium deoxycholate agar (m-CCDA), charcoal-based selective medium (CSM) and charcoal, cefazolin, sodium deoxycholate agar (CCDA) produced the highest recovery rate with the greatest suppression of other fecal flora. Yang Chih-Shih and coworkers (2000) evaluated the API-Campy Identification kit (Biomerieux, Marcyl'Etoile, France) for its applicability and compared the efficacy of three selective media 
(charcoal, cefoperazone, sodium deoxycholate agar (m-CCDA), Campy-Cefex agar (CCA) and charcoal-based selective medium (CSM)); they observed no differences. The API-Campy kit efficiently detected 87 Campylobacter spp. isolates from chicken samples examined with $100 \%$ agreement at the genus level and up to $94 \%$ at the species level when compared to conventional methods.

Hodge and Terro (1984) compared isolation of C. jejuni from human fecal specimens by direct inoculation on selective Columbia agar and liquid enrichment medium. They found that the liquid enrichment medium produced a $30 \%$ higher isolation rate for $C$. jejuni. The overall isolation rate achieved by both methods was $8.2 \%$ for 1,249 specimens. Agulla and coworkers (1987) evaluated the growth of Campylobacter on alkaline peptone water (APW), Bruce-Zochowsky medium broth (BZ), Campylobacter enrichment broth (CEB) and Campy-thio broth (CT). C. jejuni was isolated from 43 of 359 specimens with CT, 45 with APW, 46 with BZ and 46 with CEB. No significant differences were found for the number of isolates obtained with and without enrichment procedures. In 1983, Fricker and Girdwood compared enrichment of fecal samples for Campylobacter to direct plating on Preston and Skirrow media. Enrichment culture had little effect on the frequency of Campylobacter from most patients with acute diarrhea, provided that good selective medium is used and that the delay in culturing specimens is minimal. In 1983, Hutchinson and Bolton examined the role of enrichment culture in isolation of $C$. jejuni from feces. They reported that enrichment culture was only necessary for specimens when the number of organisms is likely to be low. Martin and coworkers (1983) tested a new selective enrichment broth for the isolation of C. jejuni from fecal specimens of human, poultry and bovine origin. Compared to direct plating, 
the new enrichment increased isolation rate of $C$. jejuni by $46.3 \%$. In 1984, Francis and colleagues demonstrated the advantage of using enrichment-culture techniques to isolate C. jejuni from stools. Data indicated that enrichment broth supplemented with antibiotics markedly increased Campylobacter isolation rate. In 1985, Garcia and coworkers examined, by direct plating and enrichment techniques, the prevalence and distribution of C. jejuni and C. coli at various sites in the digestive tract of cattle. Isolates were found 40.2\% more frequently when enrichment techniques were used. Humphrey (1989) appraised the efficacy of pre-enrichment for isolation of Campylobacter jejuni from food and water. With the broth culture, isolation could be increased by pre-enrichment in basal or selective media at $37^{\circ} \mathrm{C}$ for 4 hours. Jeffrey and colleagues (2000) studied production of an economical, easy to prepare field-suitable enrichment medium for detection of $C$. jejuni in small numbers. The medium was able to detect, with $75 \%$ accuracy, Campylobacter at $10^{0}$ and $10^{1}$ dilution rates. When challenged by inclusion of E. coli, the recovery rate was 50 to $100 \%$ when the medium was inoculated with one to 1 million $\mathrm{cfu} / \mathrm{ml}$.

Due to advances in technology, molecular techniques have been developed to identify Campylobacter. In 1997, Linton and coworkers evaluated newly designed PCR techniques for detection and identification to the species level and for typing of Campylobacter directly from human fecal specimens. Out of 20 clinical samples from which Campylobacters had been cultured, C. jejuni was in 17, C. coli in 2 and coinfection of C. jejuni and C. hypointestinalis in 1 sample. Results agreed with culture and phenotypic identification to the species level. Lawson and coworkers (1997) developed a rapid and simple PCR assay for detecting and differentiating C. upsaliensis and $C$. 
helveticus in fecal samples. The PCR assay was compared with culture detection by a membrane filter technique and a selective agar containing cefoperazone. The PCR assay and membrane filter technique were similar in isolation rates. The selective agar could detect Campylobacter at lower levels than the PCR assay, but the PCR assay only took 8 $\mathrm{h}$ for results; the selective agar and membrane filter technique required 48 to $96 \mathrm{~h}$ in a microaerophilic environment to culture Campylobacter. Thunberg and coworkers (2000) compared detection efficacy of a PCR technique with a standard plating method for detection of $C$. jejuni in a variety of foods. Charcoal and iron used in the enrichment broth interferes with the PCR assay. Once the problem was corrected, there was virtually no difference in detection of $C$. jejuni among enriched samples analyzed by PCR and the selective agar isolation (SAI) method. Using $48 \mathrm{~h}$ enriched cultures in combination with PCR analysis could possibly save one day in the time required for presumptive identification of $C$. jejuni in suspected foods. Nielsen and coworkers (2000) compared 6 methods for subtyping C. jejuni isolates from animal, human and water outbreaks. All isolates were typeable by each of the 6 methods.

Stern and Robach (1995) evaluated non-destructive sampling methods (i.e., fecal droppings, cecal droppings and cloacal swabs) to monitor the presence of Campylobacter spp. in broiler chickens. During an entire growout period, $45 \%$ of 964 fecal droppings, $58 \%$ of 284 cecal droppings and $41 \%$ of 786 cloacal swabs presented positive isolates of Campylobacter spp. Sampling of cecal droppings was the most sensitive, non-destructive sampling method. In 1990, Arimi and coworkers investigated the haemolytic activity, on blood agar plates, of some Campylobacters to determine if haemolysis might be a useful aid in strain differentiation. Distinct haemolysis occurred for $92.3 \%$ of $C$. jejuni and 
$21.7 \%$ of C. coli strains on sheep blood heart infusion agar incubated for $4 \mathrm{~d}$ microaerophilically at $42^{\circ} \mathrm{C}$. Haemolysis was also detected when horse blood heart infusion agar was used. No other strains of Campylobacter tested were haemolytic. The plate haemolysis test may aid differentiation within the thermophilic Campylobacters. On and Holmes (1991) studied data on reproducibility using three different basal media for tolerance tests. Reproducibility of the tests with each medium exceeded $89 \%$. The proportion of strains able to grow in a reproducible manner on the basal media varied from $100 \%$ for blood agar, to $50 \%$ for nutrient agar, to $5 \%$ for brucella agar. In 1992 , Doyle and Roman provided information on the response of Campylobacter and nalidixic acid-resistant, thermophilic Campylobacter to sodium chloride at 4,25 and $42^{\circ} \mathrm{C}$. Growth occurred at $42^{\circ} \mathrm{C}$ in $1.5 \% \mathrm{NaCl}$, but not at $2.0 \%$. At the same temperature nalidixic acid-resistant, thermophilic Campylobacter could grow in $2.0 \% \mathrm{NaCl}$ and was tolerant up to $4.5 \%$. At $4{ }^{\circ} \mathrm{C}$, all strains were sensitive to $1.0 \% \mathrm{NaCl}$ and higher, but cell death was slower than what was observed at $25^{\circ} \mathrm{C}$ at a constant level of sodium chloride. Saha and colleagues (1991) studied the ability to resuscitate freeze-thaw injured C. jejuni strains to a fully virulent form. After thaw, direct plating did not demonstrate growth. When 16 freeze-thaw injured C. jejuni strains were passed through rat guts for $18 \mathrm{~h}$, seven strains were resuscitated. After consecutive samplings, Campylobacter strains regained full virulence capacity. In 1999, Doan and colleagues determined the relative recoveries of important periodontal bacteria in Coy anaerobic chambers, Gas Paks and AnaeroPack culture systems. The Coy anaerobic chamber yielded the highest proportional recoveries of Campylobacter, which is considered one of the important periodontal bacteria. 


\section{Chapter 1}

Determining possible effects of Campylobacter on a turkey production facility 


\section{Introduction:}

Colonization of birds by Campylobacter predisposes the carcass to contamination during processing and increases the potential to cause disease in humans. Initially, Campylobacter was known as Vibrio and thought to only pose risk to cattle and sheep where stillborn deaths were experienced. Campylobacter, $0.5 \mu \mathrm{m}$ wide and $5.0 \mu \mathrm{m}$ long, requires a microaerophilic environment $\left(85 \% \mathrm{~N}_{2}, 10 \% \mathrm{CO}_{2}\right.$ and $\left.5 \% \mathrm{O}_{2}\right)$ (Hensyl, 1994). It relies on a form of metabolism that uses amino acids and tricarbocylic acid cycle intermediates for energy. These requirements make the intestinal tracts of most mammalian and avian species ideal for Campylobacter colonization. As a result, poultry share a commensal relationship with Campylobacter. This type of a relationship causes no harm to the host (the host being the bird), but still provides the nutrients needed for Campylobacter to survive. The kind of relationship poultry has with Campylobacter makes it a major reservoir for this pathogen. Stern and coworkers (1992) stated, "The first report on the presence of Campylobacter jejuni associated with chicken carcasses was discovered by Smith and Muldoon". Recent studies have reported levels of Campylobacter from 8.1 to $100 \%$ in poultry (Quinines-Ramirez, et al., 2000). Campylobacter has been isolated at all phases of poultry production, from the live bird throughout the production cycle to the retail products sold in supermarkets (Doyle, 1994). Neill and colleagues (1984) evaluated broiler chickens for C. jejuni colonization. They found that 10 of 12 flocks sampled did not produce positive samples when chicks were at 2 weeks of age. As the birds aged, the flocks became colonized, but the source of colonization could not be found. Stern and coworkers (1995) studied the role of transport and holding on Campylobacter colonization rates. In their results, they found that 9 of 10 
farms sampled had broilers contaminated with Campylobacter. When birds were examined before and after transport and holding, a higher level of contamination occurred in birds that had been transported and held. Pearson and colleagues (1993) investigated an outbreak of $C$. jejuni in Bournemouth, United Kingdom. The outbreak was associated with a catering college that was supplied chicken from a single wholesaler. Pearson and colleagues traced the C. jejuni back to a farm that had a contaminated water supply.

Many health risks are possible if food is not prepared properly since as few as 500 Campylobacter cells can cause infection. Symptoms of an infection usually consist of headaches, muscle pain, nausea, fever and bloody diarrhea. The Food and Drug Administration estimates that 2 million individuals become infected with Campylobacter annually, resulting in approximately 500 deaths. The United States Department of Agriculture estimates the annual cost due to infections by Campylobacter at 0.7 to 4.3 billion dollars. In order to reduce Campylobacter in turkey products, the frequency of Campylobacter colonization in live turkeys must be reduced. The objectives of this study were to 1) determine the level of Campylobacter throughout turkey production, 2) to assess strain and gender effects, and 3) to determine when the flock becomes colonized. Our goal was to determine when and where preharvest controls could be implemented to reduce the frequency of Campylobacter. In conclusion by possibly chlorinating the water in the house while birds are in pens, dipping boots before and after entering the house at all times and using methods like competitive exclusion when poults are first hatched may reduce the frequency of Campylobacter or even eliminated it. It was best said by Bailey 
(1993), "The only method to reduce or eliminate C. jejuni at the processing plant is to achieve a bird that is $C$. jejuni free". 


\section{Material \& Methods}

\section{Placement}

Three flocks were examined from May 2000 to March 2001. The first 2 flocks were housed for a period of 6 weeks and for each flock, poults were placed in the house at 2-3 days of age and removed 6 weeks later. Flock 1, occupied 12 pens within the facility (Fig. 1) and was placed on fresh wood shavings. Flock 1 (F1) was sampled at weeks 0,3 and 6 of production. Flock 2, also occupied 12 pens within the facility (Fig. 1) and were placed on used wooden shavings after removal of F1 birds. Litter was aerated and disinfected with TEMPO ${ }^{\circledR}$, an insecticide, before the placement of F2. Samples from F2 were collected on weeks $0,1,2,3$, and 6 of production. Poults in flock 3 (F3) were housed from 2-3 days of age to 20 weeks, and they were placed in two stages, designated as placement 1 and 2 (Fig. 2). Placement 1 was located at the south end of the facility, and placement 2 poults were housed on the north end of the facility 4 weeks later. First placement poults were sampled at weeks $0,4,7,12,18$ and 20, and second-placement poults were sampled at weeks $0,3,5,8,14$ and 20. At week 0 for each flock, gastrointestinal tracts and box liners were sampled, and for all other periods, fecal droppings and water from drinkers were sampled. Due to the separation between placement of the F3 poults, data were collected from both ends of the building and compared (Fig. 2). The F3 sampling schedule was performed in the manner previously described to allow for both placements to be sampled on one day when overlap began in the production of the birds. Fresh wood shavings were provided as litter before poults arrived for F3 placements. 


\section{Sample Collection and Transport}

Samples consisted of gastrointestinal tracts (GI), box liners, drinkers and fecal droppings. Throughout the study, all flocks were sampled in the same manner. On week 0 , entire gastrointestinal tracts and $5 \mathrm{~cm}^{2}$ sections of box liner were sampled.

For GI tracts, poults were euthanized by cervical disarticulation. A thin layer of skin was removed from the tip of the keel to the base of the neck, and cranially, to the cloaca, caudally, exposing the breast and abdomen. The abdominal cavity was opened with sterile scissors to expose the GI tract. The GI tract was aseptically removed with a pair of sterile tweezers, it was cut into pieces and placed in a stomacher bag (Fisher Scientific, Pittsburgh, PA). Nutrient broth (NB) \# 2 (Appendix III), was added (100-mL) to each bag containing GI tracts and sealed with an ANPRO bag sealer. Bags with GI tracts were placed on ice for transportation.

A $5-\mathrm{cm}^{2}$ section was removed from each box liner with sterile scissors. Once removed, it was placed inside a stomacher bag with $25 \mathrm{ml}$ of NB \#2. The bag was sealed by the bag sealer and placed on ice for transport.

Fecal droppings and drinker samples were collected throughout the remainder of the production period for each flock. During this collection process, 5 fecal droppings and one drinker sample was collected from each pen. Warm and moist fecal samples were collected in sterile Whirl-pak® bags (Fisher Scientific, Pittsburgh, PA), using sterile gloves and samples were placed on ice for transport. Sampling drinkers consisted of collecting $100-\mathrm{mL}$ of water from each drinker with a $50-\mathrm{mL}$ pipette. These samples were stored in a 250-ml sterile plastic bottle and placed on ice for transport. Samples were 
transported from the Reymann Memorial farm in Wardensville, WV to the West Virginia University Poultry lab in Morgantown, WV, and transport did not exceed $3.5 \mathrm{~h}$.

\section{Isolation and Confirmation}

GI tracts were placed in a stomacher blender (Model 400,Tekmar, Fisher Scientific, Pittsburgh, PA) and mixed for $30 \mathrm{~s}$. Following mixing, $0.1 \mathrm{~mL}$ was plated onto a CampyCefex agar (Appendix II) plate. Box liner samples were placed in a sterile stomacher bag and blended for $30 \mathrm{~s}$. Following thorough mixing, $0.1 \mathrm{~mL}$ was directly plated onto a Campy-Cefex agar plate. For fecal samples, $1 \mathrm{~g}$ was combined with $10 \mathrm{~mL}$ of NB \#2 (Appendix III) in a Whirl-pak ${ }^{\circledR}$ bag (Fisher Scientific, Pittsburgh, PA). The sample was hand massaged for $30 \mathrm{~s}$, and a $0.1 \mathrm{~mL}$ sample was directly plated on a Campy-Cefex agar plate. For drinker samples, $50 \mathrm{~mL}$ of the $100 \mathrm{~mL}$ water sample was poured into a Gelman 300 mL, magnetic filter funnel (Gelman, Ann Arbor, MI). The sample was filtered through a $47 \mathrm{~mm}$ diameter, 0.45 um grid GN-6 metrical sterile filter (Gelman, Ann Arbor, MI). Once filtered, the filter was aseptically transferred, face down, to a Campy-Cefex agar plate. All agar plates were placed in a $3.79 \mathrm{~L}$ zip-lock ${ }^{\circledR}$ bag. Each bag, containing 10 plates, was flushed with microaerophilic air $\left(85 \% \mathrm{~N}_{2}, 10 \% \mathrm{CO}_{2}\right.$ and 5\% $\mathrm{O}_{2}$ ), sealed, and placed into an Imperial II incubator 422 (Labline Instruments, Inc., IL) for $36 \mathrm{~h}$ at $42^{\circ} \mathrm{C}$. After $36 \mathrm{~h}$, plates were examined for small, white, translucent colonies. Plates showing no characteristic colonies or no growth were discarded. Plates showing characteristic colonies were saved and a colony was picked and streaked to isolation onto a fresh Campy-Cefex agar plate. Once all plates were streaked to isolation, they were again placed into a 3.79L zip-lock® bag, flushed with microaerophilic air and returned to the Imperial II incubator 422 (Labline Instruments, Inc., IL) for an additional 
24-h at $42^{\circ} \mathrm{C}$. After $24 \mathrm{~h}$, plates were again examined for characteristic small white translucent colonies. If plates had no growth, plates from the previous incubation period were used to streak for isolation again to confirm that the first transfer missed no bacteria. All plates showing characteristic colonies were confirmed as Campylobacter by selecting a single colony, in some cases 2-3 colonies, and using a campy latex agglutination test (Appendix IV) which is specific for C. jejuni, C. laridis and C. coli.

\section{Long-term Storage}

A single colony, from the same area of the plate that the colony for confirmation was selected, was transferred to a tube containing Protect beads (Appendix V). The tube was sealed and shaken 6 to 7 times and glycerol was aspirated off. All samples were stored at $-80^{\circ} \mathrm{C}$ until needed.

\section{Statistical Analysis}

A strait forward-randomized design was used to evaluate the data from both 6-week trials to test the effect of flock on frequency of detection. Orthogonal comparisons were used to test linear and quadratic relationships between frequency of colonization and week of production. For the 20 -week flock, a randomized complete block design with a split plot arrangement of treatments was employed. The whole plot factor was 2 line X 2 gender treatment combinations and the subplot factor was sampling period. The survey was repeated twice; once on the northern end and once on the southern end of the facility (Fig. 2). For each placement, 3 replications of the $2 \times 2$ combination was used with pen as the experimental unit. Analysis of variance was performed using Proc GLM of SAS and linear, quadratic, and cubic effects were tested for effect of time on frequency of detection (SAS version 8, SAS Institute Inc., Cary, NC, USA. 1999). 


\section{Results}

\section{Six-week Production Study}

In the first phase, frequency of Campylobacter isolation was affected by time for both six-week flocks (Table. 1). At week 0, all samples collected from both flocks were Campylobacter negative (Table 1). Sixty-five percent of the F1 fecal droppings were positive by week 3 of production. Campylobacter peaked at week 3 for flock 1 .

Frequency of Campylobacter detection then began a gradual decline over time. By week 6 frequency of Campylobacter detected had dropped to 55\%. In F2, a similar pattern of Campylobacter detection was observed. However, F2 had lower numbers of positive samples than F1. By week 3, 8.3\% of the F2 fecal droppings collected were confirmed positive. Frequency of detection decreased to $0 \%$ by week 6 . This decrease can not be explained by the data collected in this study. Lower levels of detection in F2 may have been due to housing. Flock 2 was housed on previously used litter. Although the litter had been treated with TEMPO ${ }^{\circledR}$, an insecticide, and aerated, it may have been possible for poults to obtain existing microflora from the litter. This mature microflora may have out competed Campylobacter in the GI tract, resulting in reduced colonization. Campylobacter was not isolated from drinker samples (Table. 1) in F1 until week 6 of the production cycle. At week 6 , the frequency of Campylobacter isolation was $41.7 \%$. In F2, drinker samples were contaminated with Campylobacter by week 3 at a frequency of $25 \%$. Detection declined over time to $16.7 \%$ by the end of the production cycle. The peak and subsequent decline in the frequency of Campylobacter in drinker samples of F2 coincided with fecal dropping data. 


\section{Twenty-week Production Study}

In the second phase of the study, a 20-wk production cycle was evaluated. Data sets were collected and compared on $1^{\text {st }}$ and $2^{\text {nd }}$ placement poults in the southern and northern ends of the facility, respectively. For both placements, week-0 samples were negative (Table. 2). Frequency of Campylobacter detection in fecal droppings was $100 \%$ by week 4 of production (Table. 2). Frequency of Campylobacter declined gradually, and by the end of the production cycle, week-20, positive samples had fallen to 55\% (Table. 2). In the second placement birds, a slower rate of colonization was observed. The majority of the birds were colonized at week 5, and frequency of Campylobacter detection increased to $93.3 \%$ by week 8 . Frequency of Campylobacter detection declined to $50 \%$ by week 20 (Table. 2). A similar trend was observed among drinker samples for both placements. Positive samples peaked between weeks 4 and 5 and then gradually declined throughout the remainder of the production cycle. Frequency of positive drinkers did not fall below $50 \%$ except at week-7 of production, where the frequency of Campylobacter dropped to $41.7 \%$ (Table. 2). Perhaps this was due to farm personnel cleaning the drinkers prior to week 7 sampling. The effect of gender was evaluated and the data indicated that tom turkeys had a slightly higher frequency of Campylobacter than hen turkeys, $57.5 \%$ compared to $55.3 \%$ respectively. These data do not agree with data collected in a preliminary study carried out earlier in 1999 (Appendix X). In the preliminary study, tom turkeys had a frequency of Campylobacter at $40 \%$ and hens had a frequency of $22.5 \%$. The studied indicated that tom turkeys carry a higher frequency of Campylobacter compared to hens, which was not seen in this study. An explanation for the increased frequency of Campylobacter seen in tom turkeys of the preliminary study may have been 
due to the fact that genders were separated by putting toms on one side of the house and hens on the other. In this study, toms and hens were only separated by pens, allowing for toms and hens to be influenced by the presence of one another. This influence may have allowed for cross contamination to occur or stress to build in the birds resulting in a weaker defense against the pathogen. Two distinct lines of turkeys were also compared in this study. T1 and Big 6 turkeys were housed in alternating pens in the facility. Pen assignments are shown in (Appendix III). Frequency of Campylobacter detection was not affected by gender, but the Big 6 line showed a slightly higher level than the T1 line, $(57.2 \%$ versus $55.6 \%)$. 


\section{Discussion}

Our data show that Campylobacter is a food safety challenge to the industry. It is currently being isolated from turkeys as it has been in chickens for the past several years. This study indicated that flocks became colonized with Campylobacter by 3 to 4 weeks of production. Our findings are in agreement with many other related studies (Acuff, et al., 1982;and Jacobs-Reitsma, et al., 1995). These investigators found that, in both broilers and turkeys, the majority of colonization occurs between 3 to 4 weeks of production. By weeks 3 to 4 , the majority of the water samples became colonized, and the frequency of Campylobacter declined gradually in later weeks. Pearson and coworkers (1993) reported that water is a major source by which whole flocks of poultry become colonized with Campylobacter.

Data from this study showed that gender and line had no effect on the frequency of Campylobacter detected. In a preliminary study (Appendix X), an increase in the frequency of Campylobacter was seen in the toms, when compared to hens. This discrepancy in our findings may have been due to the arrangement of the birds in the house, since in F3 birds, toms and hens were placed adjacent to each other and in the preliminary study the toms were on one side of the house and hens were on the other. Tom turkeys may contribute to the frequency of Campylobacter found in the hens due to cross contamination between pens or that when genders are mixed, a higher level of excitement is reached amongst the birds making them more susceptible to this pathogen.

The data from this study failed to indicate a route whereby Campylobacter is able to colonize turkeys. In a study by Pearson and coworkers (1996) it was indicated that vertical transmission might be a route whereby Campylobacter can be transmitted, 
because high levels of Campylobacter were isolated from fecal excretions. JacobsReitsma and colleagues (1995) suggested that vertical transmission is not likely to occur. Transmission among flocks would be better explained by horizontal transmission from contaminated boots, feed, water, insects or other animals, which may come into contact with the birds. Humphrey and coworkers (1993) found that simply dipping boots into a disinfectant before entering a house could delay or possibly prevent Campylobacter from colonizing the birds. Our data indicated that turkeys placed on used litter had a lower frequency of Campylobacter than turkeys placed on fresh litter. Used litter may already contain a mature microflora. Due to this microflora, Campylobacter is out competed in the gastrointestinal tracts of turkeys, which results in the observed lower frequency. This does not suggest that the microflora out competing Campylobacter is not another pathogenic organism that can have the same effects as Campylobacter. Another possibility to why used litter has a lower frequency of Campylobacter than fresh litter may be due to its appearance. Used litter may not be as eye-catching to the poults as fresh litter, which would result in less pecking and initial colonization of the chicks, which was observed in our F2 poults. The main goal of this study was to establish baseline information on frequency of Campylobacter detection in turkeys that could assist establishment of a program to reduce or eliminate Campylobacter from turkey production facilities. In summary, the frequency at which Campylobacter was isolated supports the implementation of on-farm practices to reduce the levels of this organism in birds prior to entering the processing facility. 
Tables 


\section{Samples Collected from two 6-wk studies}

Table 1. Frequency of Campylobacter isolation from GI tracts, box liners, fecal droppings, and drinkers

\begin{tabular}{|c|c|c|c|c|c|c|c|c|}
\hline Period & \multicolumn{2}{|c|}{ GI tracts } & \multicolumn{2}{|c|}{ Box liners } & \multicolumn{2}{|c|}{ Fecal Droppings } & \multicolumn{2}{|c|}{ Water } \\
\hline \multicolumn{9}{|c|}{$\begin{array}{c}\text { no. positive/no. sampled } \\
\% \text { positive }\end{array}$} \\
\hline \multicolumn{9}{|c|}{ 1st Flock } \\
\hline $0 \mathrm{wk}$ & $0 / 36$ & $0 \%$ & $0 / 15$ & $0 \%$ & & & & \\
\hline $3 w k$ & & & & & $39 / 60$ & $65 \%$ & $0 / 12$ & $0 \%$ \\
\hline $6 \mathrm{wk}$ & & & & & $31 / 60$ & $52 \%$ & $5 / 12$ & $41.7 \%$ \\
\hline Total & $0 / 36$ & $0 \%$ & $0 / 15$ & $0 \%$ & $70 / 120$ & $58 \%$ & $5 / 24$ & $21 \%$ \\
\hline \multicolumn{9}{|c|}{ 2nd Flock } \\
\hline $0 \mathrm{wk}$ & $0 / 36$ & $0 \%$ & $0 / 15$ & $0 \%$ & & & & \\
\hline $1 \mathrm{wk}$ & & & & & $0 / 60$ & $0 \%$ & $0 / 12$ & $0 \%$ \\
\hline $2 w k$ & & & & & $0 / 60$ & $0 \%$ & $0 / 12$ & $0 \%$ \\
\hline $3 w k$ & & & & & $6 / 60$ & $10 \%$ & $3 / 12$ & $25 \%$ \\
\hline $6 \mathrm{wk}$ & & & & & $0 / 60$ & $0 \%$ & $2 / 12$ & $17 \%$ \\
\hline Total & $0 / 36$ & $0 \%$ & $0 / 15$ & $0 \%$ & $6 / 240$ & $2.5 \%$ & $5 / 48$ & $10 \%$ \\
\hline
\end{tabular}




\section{Samples collected from 20-wk study}

Table 2. Frequency of Campylobacter isolation from GI tracts, box liners, fecal droppings, and drinkers

\begin{tabular}{|c|c|c|c|c|c|c|c|c|}
\hline Period & \multicolumn{2}{|c|}{ GI Tracts } & \multicolumn{2}{|c|}{ Box liners } & \multicolumn{2}{|c|}{ Fecal Droppings } & \multicolumn{2}{|c|}{ Water } \\
\hline \multicolumn{9}{|c|}{ no. positive/no. sampled } \\
\hline \multicolumn{9}{|c|}{ 1st Placement } \\
\hline $0 \mathrm{wk}$ & $0 / 36$ & $0 \%$ & $0 / 12$ & $0 \%$ & & & & \\
\hline 4 wk & & & & & $60 / 60$ & $100 \%$ & $11 / 12$ & $91.70 \%$ \\
\hline 7 wk & & & & & $55 / 60$ & $91.70 \%$ & $5 / 12$ & $41.70 \%$ \\
\hline 12 wk & & & & & $57 / 60$ & $95 \%$ & $12 / 12$ & $100 \%$ \\
\hline $18 w k$ & & & & & $38 / 60$ & $63.30 \%$ & $9 / 12$ & $75 \%$ \\
\hline $20 w k$ & & & & & $33 / 60$ & $55 \%$ & $7 / 12$ & $58.30 \%$ \\
\hline Total & $0 / 36$ & $0 \%$ & $0 / 12$ & $0 \%$ & $243 / 300$ & $81 \%$ & $44 / 60$ & $73.30 \%$ \\
\hline \multicolumn{9}{|c|}{ 2nd Placement } \\
\hline $0 \mathrm{wk}$ & $0 / 36$ & $0 \%$ & $0 / 12$ & $0 \%$ & & & & \\
\hline $3 w k$ & & & & & $24 / 60$ & $40 \%$ & $4 / 12$ & $33.30 \%$ \\
\hline 5 wk & & & & & $47 / 60$ & $78.30 \%$ & $11 / 12$ & $91.70 \%$ \\
\hline $8 w k$ & & & & & $56 / 60$ & $93.30 \%$ & $12 / 12$ & $100 \%$ \\
\hline $14 \mathrm{wk}$ & & & & & $43 / 60$ & $71.70 \%$ & $12 / 12$ & $100 \%$ \\
\hline $20 w k$ & & & & & $30 / 60$ & $50 \%$ & $7 / 12$ & $58.30 \%$ \\
\hline Total & $0 / 36$ & $0 \%$ & $0 / 12$ & $0 \%$ & $200 / 300$ & $66.70 \%$ & $46 / 60$ & $76.70 \%$ \\
\hline
\end{tabular}




\section{Figures}


Figure 1

\section{Pen Configuration for 6-wk Trials}

North End

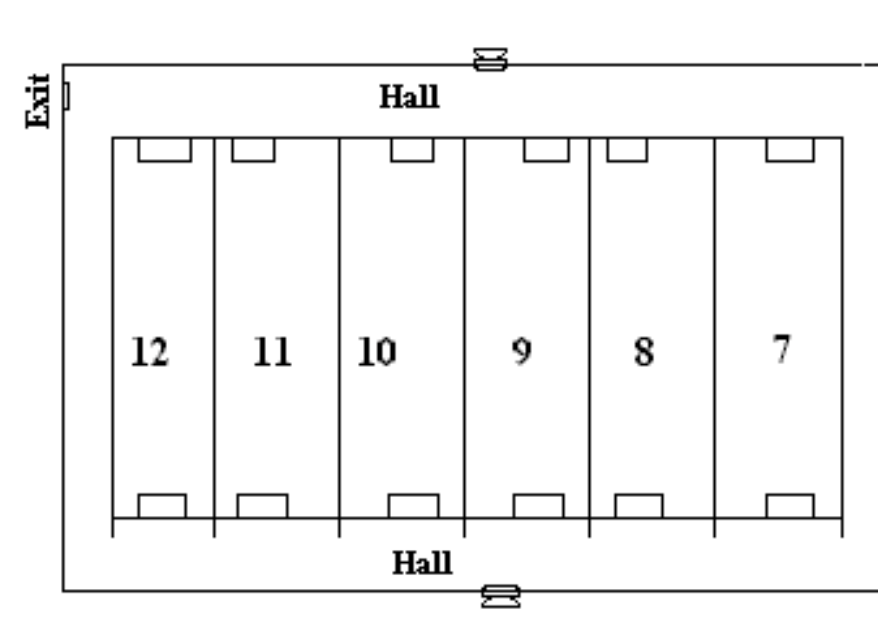

2nd half of flock
Entrance

South End
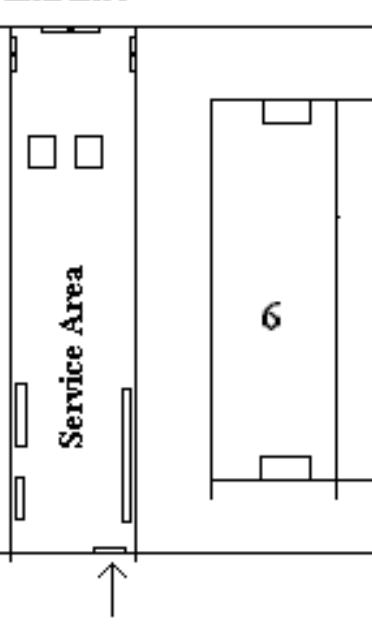

Entrance
Hall

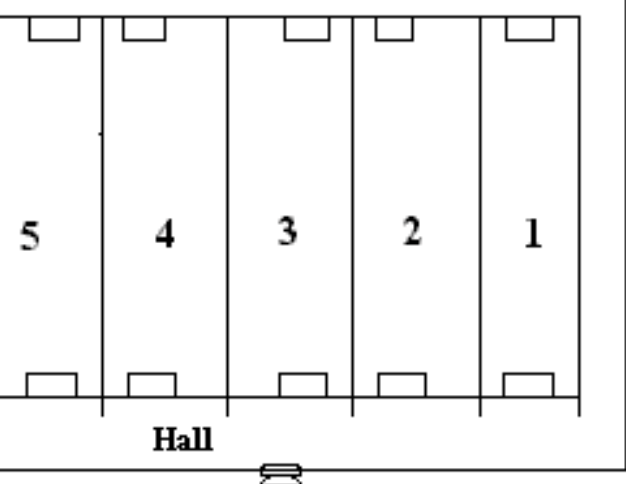

1st half of flock 
Figure 2.

\section{Housing Design for 20-wk Trial}

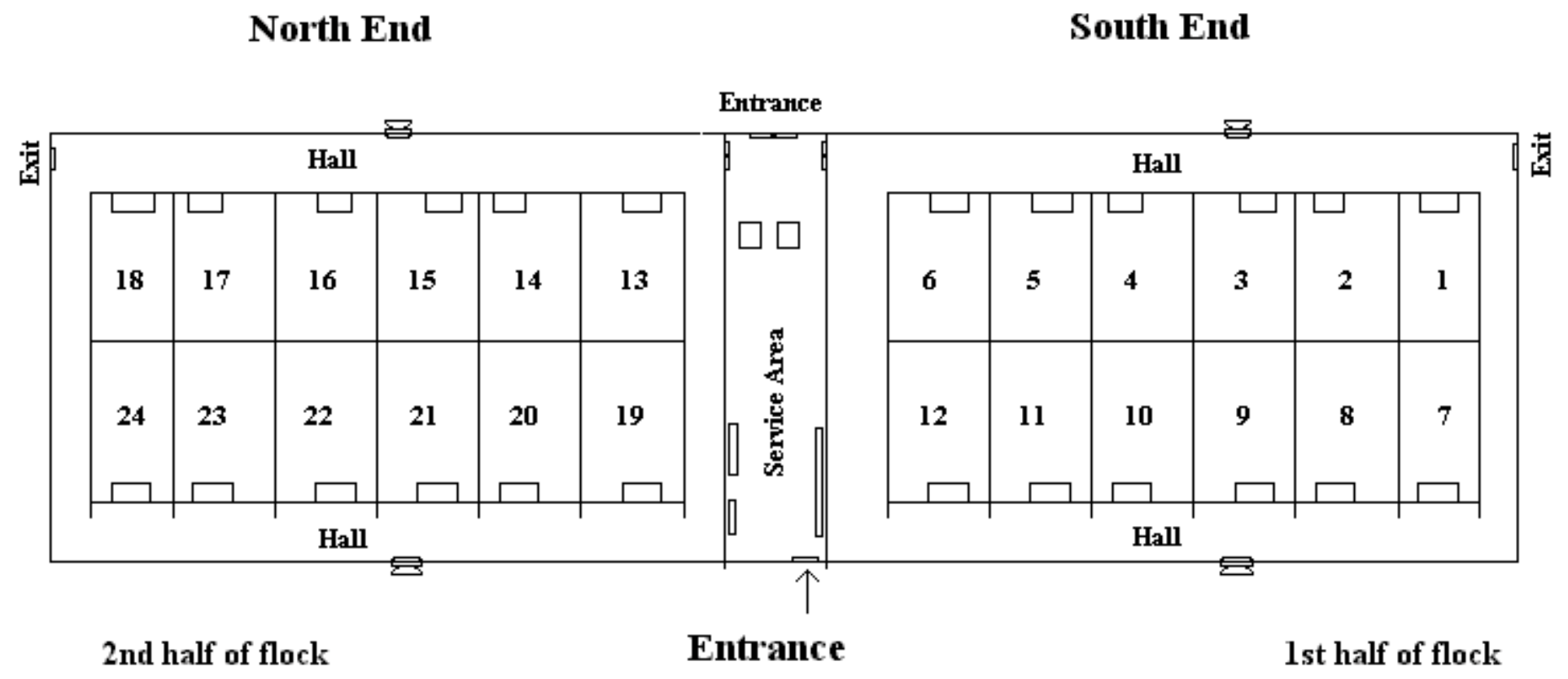




\section{Chapter 2}

Vertical Transmission as a route of Campylobacter colonization in turkeys 


\section{Introduction:}

Campylobacter colonizes the intestinal tract of poultry. Colonization by this organism may result in carcass contamination during processing and it may potentially spread and cause disease in humans. Initially, Campylobacter was known as Vibrio and only posed risk to cattle and sheep where stillborn deaths were experienced. Since the 1970 's, research on this pathogen has been extensive. It is known that poultry shares a commensal relationship with Campylobacter, thus making poultry a major reservoir for this pathogen.

The actual pathway whereby poultry become colonized is still an enigma. Many studies have looked at vertical transmission as the pathway by which colonization occurs. Shanker and colleagues (1986) evaluated the role of vertical transmission in C. jejuni colonization of a broiler flock. They stated that, in 6 breeder flocks, $74 \%$ of the birds were confirmed positive for carrying C. jejuni. Out of 187 eggs sampled from those breeders, only 2 were identified as Campylobacter carriers. Thus, vertical transmission was not considered a possible route of infection in broilers. Acuff and coworkers (1982) looked for Campylobacter in turkey eggs, poults and brooding houses. When fertile eggs and newly hatched poults were sampled, neither harbored Campylobacter. Pearson and coworkers (1996) sampled two hatcheries to determine if Campylobacter could be isolated. They found that the first hatchery had $17.6 \%$ Campylobacter positive samples. In the second hatchery, $42.9 \%$ of the samples were positive. These data support the idea that vertical transmission is a mechanism whereby Campylobacter colonizes chicks.

The objective of this study was to assess the possibility of vertical transmission as a pathway whereby Campylobacter colonizes turkeys. An accurate, sensitive, DNA-based 
technique known as flaA SVR (short variable region) sequence typing was used. This technique is a molecular tool that concentrates on specific flagellin genes that are highly conserved and have variable regions present. Results from the study will highlight the possibility of transmission from parents to offspring and will emphasize that for thorough control of Campylobacter in turkeys interventions must occur that prevent contamination of the egg. 


\section{Materials and Methods}

\section{Resuscitation of Environmental Samples}

Environmental samples from parent and poults were randomly selected for flaA SVR (short variable region) sequence typing. Pure cultures isolated from parent and offspring were removed from an $-80^{\circ} \mathrm{C}$ freezer and a single bead was streaked onto a Campy-Cefex agar (Appendix II) plate. Plates were sealed in a 3.79L Zip-lock® bag and flushed with microaerophilic air $\left(5 \% \mathrm{O}_{2}, 10 \% \mathrm{CO}_{2}\right.$ and $\left.85 \% \mathrm{~N}_{2}\right)$. Flushed bags were then placed into an Imperial II incubator 422 (Labline Instruments, Inc., IL) overnight at $42^{\circ} \mathrm{C}$ to allow for growth. Plates were removed after incubation and a single colony was selected and streaked to isolation on a fresh Campy-Cefex agar plate. Plates were placed in Zip-lock ${ }^{\circledR}$ bags, and bags were flushed with microaerophilic air; flushed bags were incubated for an additional $24 \mathrm{~h}$. After $24 \mathrm{~h}$, plates were removed from the incubator, and a single colony was selected from the plate and transferred to Wang's transport medium (Appendix VI). This sample was incubated for $24 \mathrm{~h}$, packed into microbiological containers, and shipped to the USDA-ARS lab in Athens, GA for flaA SVR sequence typing.

\section{Sample Preparation}

Campylobacter was streaked to isolation on a Campy-Cefex agar plate. Plates were placed in Zip-lock ${ }^{\circledR}$ bags, flushed with microaerophilic air, and incubated at $42^{\circ} \mathrm{C}$ overnight. Plates were removed the following day; one colony from the plate was selected and streaked once more to gain confluent growth on a Campy-Cefex agar plate. Plates were incubated as previously described. After $24 \mathrm{~h}$, all growth was removed from the plate with a sterile loop and transferred into a $0.6-\mathrm{mL}$ microcentrifuge tube containing $300 \mu \mathrm{L}$ of sterile water. Tubes were heated to $100^{\circ} \mathrm{C}$ for $10 \mathrm{~min}$ to allow cell walls to 
rupture. Boiled samples were stored at $4^{\circ} \mathrm{C}$ until used as a template for the polymerase chain reaction $(\mathrm{PCR})$.

\section{Polymerase Chain Reaction (PCR)}

The thermocycler was preheated and 10 microliters of the boiled sample was placed into a sterile microcentrifuge tube. Ninety microliters of a reaction premix (Appendix VII), using the FLA245FU (5'CTA TGG ATG AGC AAT TWA AAA T3') and FLA625RU (5'CAA GWC CTG TTC CWA CTG AAG3') primers (Meinersmann, et al., 1997), were added to the tube, and the mixture was covered with 2 drops of sterile mineral oil in place of a heated lid. The microcentrifuge tubes were capped and placed in a Perkin-Elmer 480 thermocycler (Perkin-Elmer-Applied Biosystems Inc., Foster City, CA.) programmed for a 35-cycle reaction system. The 35-cycle reaction was 1 min for denaturing at $96^{\circ} \mathrm{C}, 1 \mathrm{~min}$ for annealing at $52^{\circ} \mathrm{C}$, and $1 \mathrm{~min}$ for extension at $72^{\circ} \mathrm{C}$, yielding an approximate $425 \mathrm{bp}$ product. Product was purified to remove excess primers, dNTP's, and buffers using a QIAquick PCR purification kit (Qiagen Inc., Chatsworth, CA). Purified samples were sent to a core lab facility and sequenced using either the FLA242FU primer or the FLA625RU primer with the Big-Dye Dye-Terminator Cycle Sequencing Kit (ABI-PE, Foster City, CA). Data were assembled with Sequencher 4.1 (GeneCodes Corp., Ann Arbor, MI) and aligned using ClustalX (Thompson, J., et al., 1994). Once samples were sequenced and aligned, they were compared. Dendograms were generated using the unweighted pair-group method with arithmetic means (UPGMA) algorithm with HKY85 distance measurements in phylogentic analysis using parsimony (PAUP® 4.0) (Swofford, D., 1988). 


\section{Results}

The analysis of DNA sequences was exhaustive (repeated many times), using a variety of different algorithms. Analyses performed on the sequences were Parsimony analysis, Absolute distance measurements and unweighted pair-grouped method with arithmetic means (UPGMA) cluster analysis. All analyses resulted in identical dendograms. The dendogram (Fig. 1) indicated there were 5 instances among the parent flock samples where more than one isolate had a sequence identical to another isolate being sampled. These relationships are clonal, thus there were 5 multiple clones. Six multiple clones were found among samples collected from the offspring. Most offspring samples were found to have identical flaA SVR, DNA sequences when compared to parent samples. Identical DNA sequences indicated that samples were clonal (closely related) to each other. Offspring samples $075,077,084,101$, and 105 , which contained identical sequences to each other and samples 081, 092, and 095, which also contained identical sequences to each other, showed no relationship to any of the parental genotypes. This indicated that those offspring samples were distantly related to parent isolates sampled in this study. Parent samples 007 and 033 had genotypes that were distantly related to all offspring samples analyzed in the study. Additionally, parent sample $003,028,029$, and 034 are closely related, one base-pair difference, to offspring samples 043, 044, 048, 055, 056, 059, 061, 062, 064, 065, 068, 071, 074, 080, 087, 088, 091, 093, 096, 102, and 103. This close relationship between parent and poult samples suggests these isolates may be clonal, this base-pair difference may be due to genetic drift (random mutation). 


\section{Discussion}

Vertical transmission of Campylobacter in turkeys is not defined. Scientists have suggested that vertical transmission is a likely pathway whereby colonization occurs, but data have been limited to support this hypothesis. Jacobs-Reitsma and colleagues (1995) investigated the role of breeder flocks in the epidemiology of Campylobacter in poultry production. Campylobacter colonization of breeder flocks suggested a potential role for vertical transmission, but serotype data were not supportive. Shanker and coworkers (1986) evaluated the role of vertical transmission in C. jejuni colonization of broiler breeder flocks. Out of 187 eggs sampled from 6 breeder flocks, 2 were identified as Campylobacter carriers. Thus, vertical transmission was ruled out as a possible route of contamination.

Advances in technology occur every day, such as faster, more reliable and more sensitive techniques to identify bacteria. These techniques facilate the search for pathways whereby Campylobacter colonizes turkeys. Wassenoar and Newell (2000) stated that there are two methods generally accepted for serotyping, the Penner scheme and Loir scheme. Both techniques give high numbers of untypible strains and are time consuming and technically demanding. Recently, molecular subtyping methods have been developed. These genotyping techniques may become universally available making them a major advantage over older techniques.

The discovery of the flagellin genes in Campylobacter that have highly conserved and variable regions facilitated development of DNA-based methods for genotyping. In 1997, Stern and colleagues were able to determine potential reservoirs of Campylobacter spp. by comparing flagellin A gene of isolates from broiler production facilities. 
Camarda and coworkers (2000) also used the flagellin genes to investigate C. jejuni isolates from the intestines and oviducts of laying hens. Tsang and colleagues (2001) used the flagellum as a potential marker for C. jejuni strains associated with GuillainBarre' syndrome.

In this study, the flaA SVR sequence typing technique was used to investigate the role of vertical transmission in turkeys. Out of 81 samples evaluated, 5 multiple clones were found within the parent flocks and 6 multiple clones were found among offspring samples. Our data indicate that most offspring samples were identical to the parent samples and clonal (closely related).

The goal of this study was to evaluate the possible role of vertical transmission in turkeys, which could assist establishment of a program to reduce or eliminate Campylobacter from turkey production facilities. Identical isolates from parents and offspring support vertical transmission as a pathway whereby turkey flocks become colonized. Improved on-farm practices at the grandparent and parent flock levels to reduce colonization by Campylobacter are required to minimize the parent as a source of contamination. Eliminating this source will enhance the effectiveness of preharvest controls for horizontal transmission. 
Figure 
Figure 1.

\section{Unweighted pair-grouped method with arithmetic means analysis}

001 Parent Flock 002 Parent Flock 004 Parent Flock 005 Parent Flock 006 Parent Flock 008 Parent Flock 009 Parent Flock 010 Parent Flock

011 Parent Flock

012 Parent Flock

013 Parent Flock

015 Parent Flock

016 Parent Flock

017 Parent Flock 020 Parent Flock

024 Parent Flock

025 Parent Flock 026 Parent Flock 030 Parent Flock

036 Parent Flock 037 Parent Flock 040 Parent Flock

046 Week 4

066 Week 5

069 Week 5

072 Week 5

079 Week 12

085 Week 14

090 Week 14

098 Week 21

099 Week 21

2.030

104 Week 21

106 Week 21

075 Week 12

077 Week 12

084 Week 12

101 Week 21

035 Parent Flock

038 Parent Flock

047 Week 4

4.738

4.803

4.000

007 Parent Flock 033 Parent Flock 014 Parent Flock 021 Parent Flock 060 Week 7

076 Week 12 089 Week 14

094 Week 14

097 Week 21

100 Week 21

003 Parent Flock

028 Parent Flock 0.500029 Parent Flock 034 Parent Flock

082 Week 12

043 Week 4

044 Week 4

048 Week 4

055 Week 7

056 Week 7

059 Week 7

061 Week 7

062 Week 7

064 Week 7

065 Week 5

068 Week 5

071 Week 5

074 Week 5

080 Week 12

087 Week 14

088 Week 14

091 Week 14

093 Week 14

0.50096 Week 21

102 Week 21

081 Week 12

092 Week 14

095 Week 21

\section{-0.1 changes}




\section{Reference List:}

Achen, M., T. Y. Morishita, and E.C. Ley. 1998. Shedding and Colonization of Campylobacter jejuni in Broilers from Day-of-Hatch to Slaughter Age. Avian Dis. 42:732-737.

Acuff, G.R., C. Vanderzant, M.O. Hanna, J.G. Ehlers, and F.A. Gardner. 1986. Effects of Handling and Preparation of Turkey Products on the Survival of Campylobacter jejuni. J. Food Prot. 49:627-631.

Acuff, G.R., C. Vanderzant, F.A. Gardner, and F.A. Golan. 1982. Examination of Turkey Eggs, Poults and Brooder House Facilities for Campylobacter jejuni. J. Food Prot. 45:1279-1281.

Adekeye, J.O., P.A. Abdu, and E.K. Bawa. 1989. Campylobacter fetus subsp. jejuni in Poultry Reared under Different Management Systems in Nigeria. Avian Dis. 33:801-803.

Agulla, A., F.J. Merino, P.A. Villasante, J.V. Saz, A. Diaz, and A.C. Velasco. 1987. Evaluation of Four Enrichment Media for Isolation of Campylobacter jejuni. J. Clin. Microbiol. 25:174-175.

Aho, M., and J. Hirn. 1988. Prevalence of campylobacteria in the Finnish Broiler Chicken Chain from the Producer to the Consumer. Acta Vet. Scand. 29:451-462.

Appleby, M.C., B.O. Hughes, and H.A. Elson. 1992. Poultry Production Systems: Behavior, Management, and Welfare. C·A·B International, Wallingford, UK.

Arimi, S.M., R.W.A. Park, and C.R. Fricker. 1990. Study of Haemolytic Activity of some Campylobacter spp. on Blood Agar Plates. J. Appl. Bacteriol. 69:384-389.

Austic, R.E., M.C. Nesheim. 1990. Poultry Production. $13^{\text {th }}$ ed. Lea \& Febiger. 600 Washington Square. Philadelphia, PA.

Bailey, J.S. 1993. Control of Salmonella and Campylobacter in Poultry Production. A Summary of Work at Russell Research Center. Poultry Sci. 72:1169-1173.

Barot, M.S., A.C. Mosenthal, and V.D. Bokkenheuser. 1983. Location of Campylobacter jejuni in Infected Chicken Livers. J. Clin. Microbiol. 17:921-922.

Berrang, M.E., R.J. Buhr, and J.A. Cason. 2000. Campylobacter Recovery from External and Internal Organs of Commercial Broiler Carcass Prior to Scalding. Poultry Sci. 79:286-290. 
Bolton, F.J., D.N. Hutchinson, and D. Coates. 1984. Blood-Free Selective Medium for Isolation of Campylobacter jejuni from Feces. J. Clin. Microbiol. 19:169-171.

Bolton, F.J., D. Coates, P.M. Hinchliffe, and L. Robertson. 1983. Comparison of Selective Media for Isolation of Campylobacter jejuni/coli.

Butzler, J.P., M. De Boeck, and H. Goossens. 1983. New Selective Medium for Isolation of Campylobacter jejuni from Faecal Specimens. Lancet. Apr. 9(1):818.

Camarda, A., D.G. Newell, R. Nasti, and G. Di Modugno. 2000. Genotyping Campylobacter jejuni Strains Isolated from the Gut and Oviduct of Laying Hens. Avian Dis. 44:907-912.

Cawthraw, S.A., T.M. Wassenaar, R.A. Ayling, and D.G. Newell. 1996. Increased Colonization Potential of Campylobacter jejuni strain 81116 after Passage through Chickens and its Implication on the Rate of Transmission within Flocks. Epidemiol Infect. 117:213-215.

Center of Disease Control and Prevention. 2000. Division of Bacterial and Mycotic Diseases. Campylobacter. http://www.cdc.gov/ncidod/dbmd/diseaseinfo/campylobacter_g.htm

Chan, F.T., and A.M. Mackenzie. 1984. Advantage of Using Enrichment-Culture Techniques to Isolate Campylobacter jejuni from Stools. J. Infect. Dis. 149(3):481-482.

Doan, N., A. Contreras, J. Flynn, J. Morrison, and J. Slots. 1999. Proficiencies of Three Anaerobic Culture Systems for Recovering Periodontal Pathogenic Bacteria. J. Clin. Microbiol. 37:171-174.

Doyle, M.P., 1984. Association of Campylobacter jejuni with Laying Hens and Eggs. Appl. Environ. Microbiol. 47:533-536.

Doyle, M.P., and D.J. Roman. 1982. Response of Campylobacter jejuni to Sodium Chloride. Appl. Environ. Microbiol. 43:561-565.

Doyle, M.P., and D.J. Roman. 1981. Growth and Survival of Campylobacter fetus subsp. jejuni as a Function of Temperature and pH. J. Food Prot. 44:596-601.

Flynn, O.M., I.S. Blair, and D.A. McDowell. 1994. Prevalence of Campylobacter Species on Fresh Retail Chicken Wings in Northern Ireland. J. Food Prot. 57:334-336.

Food Safety and Inspection Service. 1999. Campylobacter. http://www.fsis.usda.gov/OA/background/campyq\&a.htm 
Fricker, C.R., R.W. Girdwood, and D. Munro. 1983. A Comparison of Procedures for the Isolation of Campylobacters from Seagull Faeces. J. Hyg. 91:445-450.

Garcia, M.M., H. Lior, R.B. Stewart, G.M. Ruckerbauer, J.R.R. Trudel, and A. Skljarevski. 1985. Isolation, Characterization, and Serotyping of Campylobacter jejuni and Campylobacter coli from Slaughter Cattle. Appl. Environ. Microbiol. 49:667-672.

Grados, O., N. Bravo, R.E. Black, and J.P. Butzler. 1988. Paediatric Campylobacter Diarrhoea from Household Exposure to Live Chickens in Lima, Peru. Bull. W.H.O. 66:369-374.

Grant, I.H., N.J. Richardson, and V.D. Bokkenheuser. 1980. Broiler Chickens as Potential Source of Campylobacter Infections in Humans. J. Clin. Microbiol. 11:508-510.

Gun-Munro, J., R.P. Rennie, J.H. Thornley, H.L. Richardson, D. Hodge, and J. Lynch. 1987. Laboratory and Clinical Evaluation of Isolation Media for Campylobacter jejuni. J. Clin. Microbiol. 25:2274-2277.

Harris, N.V., D. Thompson, D.C. Martin, and C.M. Nolan. 1986. A Survey of Campylobacter and Other Bacterial Contaminants of Pre-market Chicken and Retail Poultry and Meats, King County, Washington. AJPH. 76:401-406.

Hensyl, W.R., $9^{\text {th }}$ ed. 1994. Bergey's Manual of Determinative Bacteriology. pg.41, 5861. Williams \& Wilkins. 428 East Preston Street. Baltimore, Maryland.

Hodge, D.S., and R. Terro. 1984. Comparative Efficacy of Liquid Enrichment Medium for Isolation of Campylobacter jejuni. J. Clin. Microbiol. 19:434.

Hopkins, R.S., and A.S. Scott. 1983. Handling Raw Chicken as a Source for Sporadic Campylobacter jejuni Infections. J. Infect. Dis. 148:770.

Humphrey, T.J., A. Henley, and D.G. Lanning. 1993. The Colonization of Broiler Chickens with Campylobacter jejuni: some Epidemiological Investigations. Epidemiol. Infect. 110:601-607.

Humphrey, T.J. 1989. An Appraisal of the Efficacy of Pre-Enrichment for the Isolation of Campylobacter jejuni from Water and Food. J. Appl. Bacteriol. 66:119-126.

Hutchinson, D.N., and F.J. Bolton. 1983. Is Enrichment Culture Necessary for the Isolation of Campylobacter jejuni from Faeces? J. Clin. Pathol. 36:1350-1352.

Jacobs-Reitsma, W.F., 1995. Campylobacter Bacteria in Breeder Flocks. Avian Dis. 39:355-359. 
Jacobs-Reitsma, W.F., A.W. van de Giessen, N.M. Bolder, and R.W.A.W. Mulder. 1995. Epidemiology of Campylobacter spp. at Two Dutch Broiler Farms. Epidemiol. Infect. 114:413-421.

Jacobs-Reitsma, W.F., N.M. Bolder, and R.W.A.W. Mulder. 1994. Cecal Carriage of Campylobacter and Salmonella in Dutch Broiler Flocks at Slaughter: A One-Year Study. Poultry Sci. 73:1260-1266.

Jeffrey, J.S., A. Hunter, and E.R. Atwill. 2000. A Field-Suitable, Semisolid Aerobic Enrichment Medium for Isolation of Campylobacter jejuni in Small Numbers. J. Clin. Microbiol. 38:1668-1669.

Jones, D.M., E.M. Sutcliffe, R. Rois, A.J. Fox, and A.Curry. 1993. Campylobacter jejuni Adapts to Aerobic Metabolism in the Environment. Med. Microbiol. 38:145-150.

Jones, D.M., R.C. Axtell, D.V. Rives, S.E. Scheildeler, F.R. Tarver, Jr., R.L. Walker, and M.J. Wineland. 1991. A Survey of Campylobacter jejuni Contamination in Modern Broiler Production and Processing Systems. J. Food Prot. 54:259-262.

Juven, B.J., and M. Rogol. 1986. Incidence of Campylobacter jejuni and Campylobacter coli Serogroups in a Chicken Processing Factory. J. Food Prot. 49:290-292.

Kinde, H., C.A. Genigeorgis, and M. Pappaioanou. 1983. Prevalence of Campylobacter jejuni in Chicken Wings. Appl. Environ. Microbiol. 45:1116-1118.

Kramer, J.M., J.A. Frost, F.J. Bolton, and D.R.A. Wareing. 2000. Campylobacter Contamination of Raw Meat and Poultry at Retail Sale: Identification of Multiple Types and Comparison with Isolates from Human Infection. J. Food Prot. 63:1654-1659.

Kwiatek, K., B. Wojton, and N.J. Stern. 1990. Prevalence and Distribution of Campylobacter spp. on Poultry and Selected Red Meat Carcasses in Poland. J. Food Prot. 53:127-130.

Lammerding, A.M., M.M. Garcia, E.D. Mann, Y. Robinson, W.J. Dorward, R.B. Truscott, and F. Titiger. 1988. Prevalence of Salmonella and Thermophilic Campylobacter in Fresh Pork, Beef, Veal and Poultry in Canada. J. Food Prot. 51:47-52.

Lawson, A.J., D. Linton, J. Stanley, and R.J. Owens. 1997. Poymerase Chain Reaction Detection and Speciation of Campylobacter upsaliensis and C. helveticus in Human Faeces and Comparison with Culture Techniques. J. Appl. Microbiol. 83:375-380. 
Line, J.E., J.S. Bailey, N.A. Cox, N.J. Stern, and T. Tompkins. 1998. Effect of YeastSupplemented Feed on Salmonella and Campylobacter Populations in Broilers. Poultry Sci. 77:405-410.

Line, J.E., J.S. Bailey, N.A. Cox, and N.J. Stern. 1997. Yeast Treatment to Reduce Salmonella and Campylobacter Populations Associated with Broiler Chickens Subjected to Transport Stress. Poultry Sci. 76:1227-1231.

Lindblom, G.B., E. Sjogren, and B. Kaijser. 1986. Natural Campylobacter Colonization in Chicken Raised under different Environmental Condition. J. Hyg. 96:385-391.

Linton, D., A.J. Lawson, R.J. Owen, and J. Stanley. 1997. PCR Detection, Identification to Species Level, and Fingerprinting of Campylobacter jejuni and Campylobacter coli Direct from Diarrheic Samples. J. Clin. Microbiol. 35:2568-2572.

Luechtfeld, N.W., and Wen-Lan Lou Wang. 1981. Campylobacter fetus subsp. jejuni in a Turkey Processing Plant. J. Clin. Microbiol. 13:266-268.

Martin, W.T., C.M. Patton, G.K. Morris, M.E. Potter, and N.D. Puhr. 1983. Selective Enrichment Broth Medium for Isolation of Campylobacter jejuni. J. Clin. Microbiol. 17:853-855.

Merino, F.J., A. Agulla, P.A. Villasante, A. Daiz, J.V. Saz, and A.C. Velasco. 1986. Comparative Efficacy of Seven Selective Media for Isolating Campylobacter jejuni. J. Clin. Microbiol. 24:451-452.

Moreng, R.E., and J.S. Avens. 1985. Poultry Science and Production. Reston Publishing Company, Inc. Reston, Virginia.

Morishita, T.Y., P.P. Pyone, B.S. Harr, C.W. Cobb, and J.R. Clifford. 1997. Evaluation of an Avian-Specific Probiotic to Reduce the Colonization and Shedding of Campylobacter jejuni in Broilers. Avian Dis. 41:850-855.

Neill, S.D., J.N. Campbell, and J.A. Greene. 1984. Campylobacter species in Broiler Chickens. Avian Pathol. 13:777-785.

NG, Lai-King, D.E. Taylor, and M.E. Stiles. 1988. Characterization of Freshly Isolated Campylobacter coli Strains and Suitability of Selective Media for Their Growth. J. Clin. Microbiol. 26:518-523.

NG, Lai-King, M.E. Stiles, and D.E. Taylor. 1985. Inhibition of Campylobacter coli and Campylobacter jejuni by Antibiotics Used in Selective Growth Media. J. Clin. Microbiol. 22:510-514. 
Nielsen, E.V., J. Engberg, V. Fussing, L. Petersen, C.H. Brogren, and S.L.W. On. 2000. Evaluation of Phenotypic and Genotypic Methods for Subtyping Campylobacter jejuni Isolates from Humans, Poultry, and Cattle. J. Clin. Microbiol. 38:38003810.

On, S.L.W., and B. Holmes. 1991. Reproducibility of Tolerance Tests That Are Useful in the Identification of Campylobacteria. J. Clin. Microbiol. 29:1785-1788.

Oosterom, J., S. Notermans, H. Karman, and G.B. Engels. 1983. Origin and Prevalence of Campylobacter jejuni in Poultry Processing. J. Food Prot. 46:339-344.

Park, C.E., Z.K. Stankiewicz, J. Lovett, and J. Hunt. 1981. Incidence of Campylobacter jejuni in Fresh Eviserated Whole Market Chickens. Can. J. Microbiol. 27:841842.

Patterson, M.F., 1995. Sensitivity of Campylobacter spp. to Irradiation in Poultry Meat Lett. Appl. Microbiol. 20:338-340.

Patton, C.M., S.W. Mitchell, M.E. Potter, and A.F. Kaufmann. 1981. Comparison of Selective Media for Primary Isolation of Campylobacter fetus subsp. jejuni. J. Clin. Microbiol. 13:326-330.

Pearson, A.D., M.H. Greenwood, R. Kevin, A. Feltham, T.D. Healing, J. Donaldson, D.M. Jones, and R.R. Colwell. 1996. Microbial Ecology of Campylobacter jejuni in a United Kingdom Chicken Supply Chain: Intermittent Common Source, Vertical Transmission, and Amplification by Flock Propagation. Appl. Environ. Microbiol. 62:4614-4620.

Pearson, A.D., M. Greenwood, T.D. Healing, D. Rollins, M. Shahamat, J. Donaldson, and R.R. Colwell. 1993. Colonization of Broiler Chickens by Waterborne Campylobacter jejuni. Appl. Environ. Microbiol. 59:987-996.

Quinones-Ramirez, E.I., C. Vazquez-Salinas, O.R. Rodas-Suarez, M.O. Ramos-Flores, and R. Rodriguez-Montano. 2000. Frequency of Isolation of Campylobacter from Roasted Chicken Samples from Mexico City. J. Food Prot. 63:117-119.

Saha, S.K., S. Saha, and S.C. Sanyal. 1991. Recovery of Injured Campylobacter jejuni Cells after Animal Passage. Appl. Environ. Microbiol. 57:3388-3389.

Shanker, S., A. Lee, and T.C. Sorrell. 1990. Horizontal transmission of Campylobacter jejuni amongst Broiler Chicks: Experimental Studies. Epidemiol. Infect. 104:101110.

Shanker, S., A. Lee, and T.C. Sorrell. 1986. Campylobacter jejuni in Broilers: The Role of Vertical Transmission. J. Hyg. 96:153-159. 
Shanker, S., J.A. Rosenfield, G.R. Davey, and T.C. Sorrell. 1982. Campylobacter jejuni: Incidence in Processed Broilers and Biotype Distribution in Human and Broiler Isolates. Appl. Environ. Microbiol. 43:1219-1220.

Smith, J.L., and P.M. Fratamico. 1995. Factors Involved in the Emergence and Persistence of Food-Borne Diseases. J. Food Prot. 58:696-708.

Smith, M.V., II, and P.J. Muldoon. 1974. Campylobacter fetus subspecies jejuni (Vibrio fetus) from commercially processed poultry. Appl. Microbiol. 27:995-996.

Stern, N.J., M.A. Myszewski, H.M. Barnhart, and D.W. Dreesen. 1997. Flagellin A Gene Restriction Fragment Length Polymorphism Patterns of Campylobacter spp. Isolates from Broiler Production Sources. Avian Dis. 41:899-905.

Stern, N.J., M.R.S. Clavero, J.S. Bailey, N.A. Cox, and M.C. Robach. 1995. Campylobacter spp. in Broilers on the Farm and After Transport. Poultry Sci. 74:937-941.

Stern, N., 1995. Influence of Season and Refrigerated Storage on Campylobacter spp. Contamination of Broiler Carcasses. J. Appl. Poultry Res. 4:235-238.

Stern, N.J., and Robach, M.C. 1995. Non-Destructive Sampling of Live Broilers for Campylobacter. J. Appl. Poultry Res. 4:182-185.

Stern, N.J., D.M. Jones, I.V. Wesley, and D.M. Rollins. 1994. Colonization of Chicks by Non-Culturable Campylobacter spp. Lett. Appl. Microbiol. 18:333-336.

Stern, N.J., 1994. Mucosal Competitive Exclusion to Diminish Colonization of Chickens by Campylobacter jejuni. Poultry Sci. 73:402-407.

Stern, N.J., B. Wojton, and K. Kwiatek. 1992. A Differential-selective Medium and Dry Ice-generated Atmosphere for Recovery of Campylobacter jejuni. J. Food Prot. 55:514-517.

Stern, N.J., J.S. Bailey, L.C. Blankenship, N.A. Cox, and F. McHan. 1988. Colonization Characteristics of Campylobacter jejuni in Chick Ceca. Avian Dis. 32:330-334.

Svedhem, A., B. Kaijser, and E. Sjogren. 1981. The Occurrence of Campylobacter jejuni in Fresh Food and Survival under Different Conditions. J. Hyg. 87:421-425.

Tsang, R.S.W., G. Figueroa, L. Bryden, and L. NG. 2001. Flagella as a Potential Marker for Campylobacter jejuni Strains Associated with Guillain-Barre' Syndrome. J. Clin. Microbiol. 39(2):762-764.

Thunberg, R.L., T.T. Tran, and M.O. Walderhaug. 2000. Detection of Thermophilic Campylobacter spp. in Blood-Free Enriched Samples of Inoculated Foods by the Polymerase Chain Reaction. J. Food Prot. 63:299-303. 
U.S. Food and Drug Administration. 1999. Center for Food Safety and Applied Nutrition: Campylobacter jejuni. http://vm.cfsan.fda.gov/ mow/intro.html

van de Giessen, A.W., B.P. Bloemberg, W.S. Ritmeester, and J.J. Tilburg. 1996. Epidemiological Study on Risk Factors and Risk Reducing Measures for Campylobacter Infections in Dutch Broiler Flocks. Epidemiol. Infect. 117:245250.

van de Giessen, A.W., S.I. Mazurier, W. Jacobs-Reitsma, W. Jansen, P. Berkers, W. Ritmeeseter, and K. Wernars. 1992. Study on the Epidemiology and Control of Campylobacter jejuni in Poultry Broiler Flocks. Appl. Environ. Microbiol. 58:1913-1917.

Wassenaar, T.M., and D.G. Newell. 2000. Minireview: Genotyping of Campylobacter spp. Appl. Enviro. Microbiol. 66(1):1-9.

Wempe, J.M., C.A. Genigeorgis, T.B. Farver, and H.I. Yusufu. 1983. Prevalence of Campylobacter jejuni in Two California Chicken Processing Plants. Appl. Environ. Microbiol. 45:355-359.

Willis, W.L., and C. Murray. 1997. Campylobacter jejuni Seasonal Recovery Observation of Retail Market Broilers. Poultry Sci. 76:314-317.

Yang-Chih Shih, D. 2000. Isolation and Identification of Enteropathogenic Campylobacter spp. from Chicken Samples in Taipei. J. Food Prot. 63:304-308. 
Appendices 


\section{Appendix I}

\section{Pen assignment for Flock 3 20-wk Trial}

\begin{tabular}{|l|l|r|}
\hline Strain & Gender & Pens \\
\hline Line 1 & Toms & $5,7,9,17,19,21$ \\
\hline Line 1 & Hens & $2,4,12,14,16,24$ \\
\hline Line 2 & Toms & $1,3,11,13,15,23$ \\
\hline Line 2 & Hens & $6,8,10,18,20,22$ \\
\hline
\end{tabular}




\section{Appendix II}

\section{Campy-Cefex agar}

\section{Basal medium}

Brucella agar

Ferrous sulfate $\left(\mathrm{FeSO}_{4} 7 \mathrm{H}_{2} \mathrm{O}\right)$

Sodium bisulfite

$0.5 \mathrm{~g}$

Sodium pyruvate

$0.2 \mathrm{~g}$

$\mathrm{dH}_{2} \mathrm{O}$

$0.5 \mathrm{~g}$

$950 \mathrm{ml}$

\section{Supplements}

Sodium cefoperazone

Sodium cycloheximide

Lysed horse blood

$33 \mathrm{mg}$

$200 \mathrm{mg}$

$50 \mathrm{ml}$

\section{Replacement for cycloheximide}

Nystatin

Rifampicin

Stern, N.J., Wojton, B., and Kwiatek, K. 1992. A Differential-selective Medium and Dry Ice-generated Atmosphere for Recovery of Campylobacter jejuni. J. Food Prot. 55(7): 514-517. 


\title{
Appendix III
}

\section{Campylobacter Enrichment Broth}

\author{
Nutrient broth No. 2 (Oxoid) with $0.6 \%$ yeast extract \\ Lab-Lemco powder (Oxoid L29) \\ $10 \mathrm{~g}$ \\ Peptone \\ $10 \mathrm{~g}$ \\ $\mathrm{NaCl}$ \\ $5 \mathrm{~g}$ \\ Yeast extract \\ $6 \mathrm{~g}$ \\ Distilled water \\ $950 \mathrm{ml}$
}

Autoclave $15 \mathrm{~min}$ at $121^{\circ} \mathrm{C}$ in graduated bottles. Use broth within 1 month of preparation (preferably less than 2 weeks). Media will absorb $\mathrm{O}_{2}$ during storage, which can inhibit recovery of microaerophiles. Keep bottles tightly closed. Before use add 50$\mathrm{ml}$ fresh or frozen-fresh lysed horse blood (5\%), 4-ml high concentration FBP, and $4 \mathrm{ml}$ of appropriate antibiotic concentrate (solutions made separately). Store powdered media tightly closed in cool, dry area to reduce oxygen infusion and peroxide formation. Final $\mathrm{pH}, 7.5 \pm 0.2$.

Food and Drug Administration. 1992. Bacteriological Analytical Manual. $7^{\text {th }}$ Edition. AOAC International. 2200 Wilson Blvd., Suite 400 Arlington, VA 22201. 


\title{
Appendix IV
}

\author{
INDX®-Campy (jcl) ${ }^{\mathrm{TM}}$ \\ Culture Confirmation Test for \\ Campylobacter jejuni, C. coli, and C. laridis \\ Catalog \#2200-01-50
}

\section{Materials:}

INDX ${ }^{\circledR}-$ Campy $(j \mathrm{cl}){ }^{\mathrm{TM}}$ Latex Detection Reagent $(2$ X $3.50 \mathrm{ml})$ - consists of rabbit antiserum to common antigens of selected Campylobacter species bound to latex particles suspended in buffer containing a preservative.

INDX ${ }^{\circledR}-$ Campy $(\mathrm{jcl})^{\mathrm{TM}}$ Extraction Reagent $(2.80 \mathrm{ml})$ - a dilute solution of hydrochloric acid.

INDX ${ }^{\circledR}$-Campy $(j c l)^{\mathrm{TM}}$ Neutralization Reagent $(280 \mathrm{ml})$ - Glycine buffer containing a preservative.

INDX®-Campy (jcl) ${ }^{\mathrm{TM}}$ Positive Antigen Control Reagent $(2.70 \mathrm{ml})$ - consists of a neutralized acid extract of appropriate Campylobacter organisms in buffer containing a preservative.

\section{Test slide}

\section{Applicator sticks}

\section{High intensity lamp}

\section{Slide rotator}

\section{Procedure:}

1. Remove the reagents from the refrigerator and allow them to warm to room temperature before use.

2. Label one circle on the test slide for each specimen to be tested.

3. Identify one circle for the positive control and another circle for the negative control reactions.

4. Remove the cap and tip protector from the vial of Extraction Reagent. While holding the vial in a vertical position, dispense one free-falling drop of Extraction Reagent 
into each specimen circle and the negative control circle. Replace the tip protector and cap.

5. Touch one isolated colony with the end of a wooden applicator stick to remove it from the agar surface. Generally, one colony with a diameter of $2 \mathrm{~mm}$ (about the diameter of the applicator stick) will provide an adequate inoculum. If colonies are small, yet distinct from the surface of the agar, it may be necessary to pick 2-6 colonies. However, care must be taken as too much inoculum may contribute to poor readability.

6. Make a homogeneous suspension by rotating the inoculum containing stick in the Extraction Reagent within the appropriate specimen circle. It is very important to dissociate all visible clumps of the inoculum and distribute the suspension over the entire area within the circle. Repeat steps 5 and 6 for each specimen to be tested. No incubation time is required for this step. Proceed to step 7.

7. Remove the cap and tip protector from the vial of Neutralization Reagent. While holding the vial in a vertical position, dispense one free falling drop of Neutralization Reagent into the fluid spread in each specimen circle and the negative control circle. Replace the tip protector and cap.

8. Remove the cap from the Positive Control Reagent and wipe the tip with a clean lintfree tissue. While holding the vial in a vertical position, dispense one free-falling drop into the positive control circle. Replace the cap.

9. Gently resuspend the Latex Detection Reagent to assure a homogeneous suspension. Do not shake the reagent and avoid the formation of foam or bubbles.

10. Remove the cap from the Latex Detection Reagent and wipe the tip with a clean lintfree tissue. While holding the vial in a vertical position, dispense one free-falling drop of Latex Detection Reagent into each circle, as appropriate, on the slide. Avoid foaming bubbles on the dropper tip as the latex reagent is dispensed. Do not touch the tip of the dropper vial to the material on the slide. Replace the cap.

11. At this point each circle will have received the following:

$$
\begin{array}{lll}
\text { Specimen } & \text { Negative Control Positive Control }
\end{array}
$$
1. Extraction Reagent
1. Extraction Reagent
1. Positive Control Reagent
2. Colony(ies)
2. Neutralization Reagent
2. Latex Detection Reagent

\section{Neutralization Reagent 3. Latex Detection Reagent}

\section{Latex Detection Reagent}

12. Use a separate applicator stick to mix the contents of each circle thoroughly.

13. Place the slide on a rotator and rotate at $100-110 \mathrm{rpm}$ for 5 minutes at room temperature.

14. After rotation is completed, immediately observe the reactions for visible agglutination under a high intensity light. 
15. A positive test is indicated when the Latex Detection Reagent clearly agglutinates with the test specimen and no agglutination occurs in the negative control circle. The presence of agglutination in the negative control circle renders the test invalid.

16. A negative test is indicated by the absence of agglutination of the Latex Detection Reagent with the test specimen.

INDX-Integrated Diagnostics, Inc. Baltimore, MD 21227 USA. 


\section{Appendix V \\ Protect ${ }^{\mathrm{TM}}$ Bacterial Preservers}

\section{Composition:}

Protect is a sterile vial containing chemically treated porous beads in a cryopreservative fluid of TSB + glycerol with a hypertonic additive. Each bead serves as carrier for the culture during storage.

\section{Procedure for Preparation:}

1. Remove the cap being careful not to contaminate the contents. (the GRIPPER helps with this) Inoculate the PROTECT vial with young (18-24 hours) colonial growth of a pure culture of the organism being preserved, to approximate a McFarland 3-4 standard, using a sterile loop. (optional method) Use a sterile pipette to harvest and emulsify the colonies into a PROTECT vial by using a squeezing action. The same pipette may then be used to extract the excess fluid. (Step 3) Liquid cultures can be lightly centrifuged and the deposit used as above.

2. Cap the tube and invert 6 times. Do Not Vortex.

3. Let vial stand for 30 seconds. The organism will now be bound to the beads. Remove the excess cryopreservative fluid leaving the beads as free of liquid as possible. A sterile pipette is best for this procedure. Close the vial finger tight.

4. Record the culture details on the vial and store at minus $70^{\circ} \mathrm{C}$.

\section{Procedure For Use - Recovery:}

1. Remove the vial from the freezer.

2. Carefully open the vial and remove a single bead with a sterile needle, forceps, or the special PROTECT hook available from KEY Scientific.

3. Rub the bead over solid medium, streak from point of contact, or drop into appropriate growth broth. Some organisms perform better using broth method. Beads should not be returned to the vial after removal.

Medical Laboratory Sciences, 1985, 42:289-290.

Feltham et al., 1978. J. Appl. Bacteriol. 44:313-316. 


\section{Appendix VI \\ Wang's Transport Storage Media}

Brucella broth

Brucella agar

$\mathrm{DH}_{2} \mathrm{O}$

Bring mixture to a boil and autoclave

Temper solution to $50^{\circ} \mathrm{C}$

Lysed horse blood

$\mathrm{DH}_{2} \mathrm{O}$

Add diluted lysed horse blood to the tempered solution

\author{
$28 \mathrm{~g}$ \\ $4 \mathrm{~g}$ \\ $950 \mathrm{~mL}$
}

$50 \mathrm{~mL}$

$50 \mathrm{~mL}$

Correspondence:

Stern, N.J., 2000. USDA-ARS Russell Research Center 950 College Station Rd. Athens, GA 30604 


\section{Appendix VII}

\section{PCR Reaction Premix}

Prepare PCR Reaction Premix in a $1.5 \mathrm{~mL}$ microcentrifuge tube, for the appropriate number of samples. Include both a positive and a negative control. It is advisable to prepare reaction premix for one additional sample due to possible pipetting errors.

Therefore if 10 samples are to be analyzed, prepare a reaction premix for 13 samples (10 samples +1 positive control +1 negative control +1 extra sample).

\begin{tabular}{|l|c|c|c|c|}
\hline Reagent & 1 Sample & 5 Samples & 10 Samples & 20 Samples \\
\hline 10X Buffer & $10 \mathrm{uL}$ & $50 \mathrm{uL}$ & $100 \mathrm{uL}$ & $200 \mathrm{uL}$ \\
\hline $\mathrm{MgCl}$ & $6 \mathrm{uL}$ & $30 \mathrm{uL}$ & $60 \mathrm{uL}$ & $120 \mathrm{uL}$ \\
\hline dNTP mix & $8 \mathrm{uL}$ & $40 \mathrm{uL}$ & $80 \mathrm{uL}$ & $160 \mathrm{uL}$ \\
\hline Forward Primer & $0.5 \mathrm{uL}$ & $2.5 \mathrm{uL}$ & $5 \mathrm{uL}$ & $10 \mathrm{uL}$ \\
\hline Reverse Primer & $0.5 \mathrm{uL}$ & $2.5 \mathrm{uL}$ & $5 \mathrm{uL}$ & $10 \mathrm{uL}$ \\
\hline Sterile water & $64.5 \mathrm{uL}$ & $322.5 \mathrm{uL}$ & $645 \mathrm{uL}$ & $1290 \mathrm{uL}$ \\
\hline Taq Polymerase & $0.5 \mathrm{uL}$ & $2.5 \mathrm{uL}$ & $5 \mathrm{uL}$ & $10 \mathrm{uL}$ \\
\hline & & & & \\
\hline Total Volume & $\mathbf{9 0} \mathbf{u L}$ & $\mathbf{4 5 0} \mathbf{u L}$ & $\mathbf{9 0 0} \mathbf{u L}$ & $\mathbf{1 8 0 0} \mathbf{u L}$ \\
\hline
\end{tabular}

Hiett, K.L., 2001. USDA-ARS Russell Research Center.

950 College Station Rd. Athens, GA 30604 


\section{Appendix VIII}

\section{SAS Program for Analysis of Six-Week Data}

Title 'Aaron Kiess Data - Flock 1\&2 Samples From Birds';

options $1 \mathrm{~s}=\mathbf{8 0} \mathrm{ps}=\mathbf{5 2}$ pageno $=\mathbf{1}$;

proc import datafile="C: $\backslash$ My Documents $\backslash$ kiess files $\backslash$ flocks $1 \& 2$ birds.xls"

out=one

replace;

data two; set one; if week $=\mathbf{0}$ or week $=\mathbf{3}$ or week $=\mathbf{6}$;

proc sort; by flock week pen;

proc means noprint; by flock week pen; var result;

output out=three mean=Mres;

proc glm; classes flock week;

model mres= flock $\mid$ week;

contrast 'week linear' week -1 $\mathbf{0} \mathbf{1}$;

contrast 'week quadratic' week 1 -2 1;

contrast 'flock' flock -1 1;

contrast 'flock x week linear' flock*week -1 01110 -1;

contrast 'flock x week quadratic' flock*week 1 -2 1 -1 2 -1;

lsmeans flock|week;

means flock|week;

run; 
Title 'Aaron Kiess Data - Flock 1\&2 Samples From Drinkers'; options $1 \mathrm{~s}=\mathbf{8 0} \mathrm{ps}=\mathbf{5 2}$ pageno $=\mathbf{1}$;

proc import datafile="C:\My Documents $\backslash$ kiess files $\backslash$ flocks $1 \& 2$ pens.xls" out $=$ one replace;

data two; set one; if week $=\mathbf{3}$ or week $=\mathbf{6}$;

proc glm; classes flock week; model rslt= flock|week;

lsmeans flock|week;

means flock|week;

run; 


\section{Appendix VIIII}

\section{SAS Program for Analysis of Twenty-Week Data}

Title 'Aaron Kiess Data - Flock 3 Samples From Birds 3';

options $1 \mathrm{~s}=80 \mathrm{ps}=52$ pageno $=1$;

/* samples from pens; tests among genders/lines; 3 sub-blocks within each place; test linear, quadratic, and cubic effect of week*/

proc import datafile $=$ "C: $\backslash$ My Documents $\backslash k i e s s$ files $\backslash$ flock_3.xls"

out $=$ one

replace;

data two; set one; if srce="GI_tract" or srce="Fecal" then src2="Bird"; else src2="Pen";

if pen $=1$ or pen $=2$ or pen $=7$ or pen $=8$ then $B$ lock $=1$;

if pen $>=3$ and pen $<=6$ then Block $=2$;

if pen $>=9$ and pen $<=12$ then Block $=3$;

if pen $=13$ or pen $=14$ or pen $=19$ or pen $=20$ then Block $=4$;

if pen $>=15$ and pen $<=18$ then Block $=5$;

if pen $>=21$ and pen $<=24$ then Block $=6$;

if $\operatorname{src} 2="$ Bird";

proc sort; by plce block gend line pen week;

proc means noprint; by plce block gend line pen week; var rslt; output out=three

mean $=$ Mres;

data four; set three; drop_TYPE__FREQ_; proc print;

proc glm; classes plce block gend line week;

model mres $=$ plce block(plce) gend line line*gend gend*line*block*plce

week(plce) gend*week(plce) line*week(plce) line*gend*week(plce);

test $\mathrm{h}=$ gend line line*gend $\mathrm{e}=$ gend ${ }^{*}$ line*block*plce/etype $=1$;

lsmeans plce gend line week(plce);

means plce gend line week(plce)/deponly;

data five; set three; $\mathrm{Wk}=$ week; $\mathrm{WkSq}=$ week $^{* *} 2 ; \mathrm{WkCu}=\mathrm{week}^{* * 3}$;

proc glm; classes plce block gend line week;

model mres= plce block(plce) gend line line*gend gend*line*block(plce)

wk wksq wkcu week(plce);

test $\mathrm{h}=$ wk wksq wkcu $=$ =week(plce) $/$ htype $=1$ etype $=1$;

run; 
Title 'Aaron Kiess Data - Flock 3 Samples From Drinkers';

options $1 \mathrm{~s}=\mathbf{8 0} \mathrm{ps}=\mathbf{5 2}$ pageno $=\mathbf{1}$;

$/ *$ samples from pens; tests among genders/lines; 3 sub-blocks within each place; test linear, quadratic, and cubic effect of week*/

proc import datafile="C:\My Documents $\backslash k i e s s$ files $\backslash$ flock_3.xls"

out $=$ one

replace;

data two; set one;

if pen $\mathbf{1}$ or pen $\mathbf{2}$ or pen $=\mathbf{7}$ or pen $=\mathbf{8}$ then Block $=\mathbf{1}$;

if pen $>=\mathbf{3}$ and pen $<=\mathbf{6}$ then Block $=\mathbf{2}$;

if pen $>=\mathbf{9}$ and pen $<=\mathbf{1 2}$ then Block $=\mathbf{3}$;

if pen $=\mathbf{1 3}$ or pen $=\mathbf{1 4}$ or pen $=\mathbf{1 9}$ or pen $=\mathbf{2 0}$ then Block $=\mathbf{4}$;

if pen $>=\mathbf{1 5}$ and pen $<=\mathbf{1 8}$ then Block $=\mathbf{5}$;

if pen $>=\mathbf{2 1}$ and pen $<=\mathbf{2 4}$ then Block $=\mathbf{6}$;

if srce="Drinker";

proc sort; by plce block gend line pen week;

proc means noprint; by plce block gend line pen week; var rslt; output out=three mean=Mres;

data four; set three; drop_TYPE__FREQ_; proc print;

proc glm; classes plce block gend line week;

model mres $=$ plce block(plce) gend line line*gend gend*line*block*plce

week (plce) gend*week(plce) line*week(plce) line*gend*week(plce);

test $\mathrm{h}=$ gend line line*gend $\mathrm{e}=$ gend ${ }^{*}$ line*block*plce/etype $=\mathbf{1}$;

lsmeans plce gend line week(plce);

means plce gend line week(plce)/deponly;

data five; set three; $\mathrm{Wk}=$ week; $\mathrm{WkSq}=\mathrm{week}^{* * 2} \mathbf{2} \mathrm{WkCu}=\mathrm{week}^{* * 3}$;

proc glm; classes plce block gend line week;

model mres $=$ plce block(plce) gend line line*gend gend*line*block(plce)

wk wksq wkcu week(plce);

test $\mathrm{h}=$ wk wksq wkcu $\mathrm{e}=$ week(plce) $/$ htype $=\mathbf{1}$ etype $=\mathbf{1}$;

run; 


\begin{abstract}
Appendix X
Preliminary Study

Effect of gender on frequency of Campylobacter isolation from Turkeys
\end{abstract}




\begin{abstract}
Campylobacter ingestion can cause campylobacteriosis in humans and most cases have been linked to poultry products. In order to reduce Campylobacter in turkey products, frequency of Campylobacter colonization in live turkeys must be reduced. From February to March of 2000, one turkey flock at Wardensville, WV was sampled for Campylobacter. This flock was the $10^{\text {th }}$ flock produced in the facility. Samples were collected at weeks 18 and 20 of a 21 -week production cycle. The facility consisted of 24 pens, divided equally by a service area. Male and female turkeys were segregated in 12 pens on either side of the facility. Fecal droppings and drinkers were sampled to determine frequency of Campylobacter contamination. During each sampling period, for each gender, 5 fecal droppings were collected from different locations within each of the 12 pens. Thus, 120 fecal samples were collected at each sampling ( 24 pens x 5 samples). A 100-mL water sample was collected from each drinker within each pen. Fecal droppings were placed in sterile plastic bags and marked fresh or old. Drinker samples were placed in sterile bottles and all samples were transported on ice to West Virginia University for Campylobacter isolation. Water samples were mixed thoroughly; a loopful of the sample was plated directly onto a Campy-Cefex agar plate. Fecal samples were mixed with number 2 nutrient broth $(1: 10 \mathrm{w} / \mathrm{v})$. The mixture was massaged, and a loopful of the mixture was plated onto a Campy-Cefex agar plate. About 12-14 plates were placed in a 3.79L Zip-lock ${ }^{\circledR}$ bag, and the bag was sealed and incubated at 40 to $42^{\circ} \mathrm{C}$ for $48 \mathrm{~h}$. After $48 \mathrm{~h}$, plates were removed and examined for Campylobacter. Campylobacter positive colonies were round, flat, and translucent. Presumptive positives were confirmed by latex agglutination. Campylobacter was present in $26 \%$ of all
\end{abstract}


samples, and it declined from $31 \%$ at week 18 to $21 \%$ at week 20 . Campylobacter was detected more frequently in males (40\%) than in female turkey (22.5\%). Campylobacter was not detected in water collected from drinkers. Fresh fecal samples accounted for $32 \%$ of all positive samples. Frequency of Campylobacter isolation for this flock supports implementation of on-farm practices to reduce levels of Campylobacter in birds going to processing facilities. 


\section{Introduction}

Campylobacter is a leading cause of foodborne illness in the United States. It is responsible for infecting over 2 million people each year with an infection known as campylobacteriosis (Center of Disease Control and Prevention. 2000). Humans ingesting fewer than 500 cells may experience symtoms such as fever, headache, stomach pain, bloody diarrhea and in a few cases Guillan-Barre' Syndrome (GBS) which may cause

paralysis (Patterson, 1995). Campylobacter is transmitted through foods of animal origin that have been undercooked and/or mishandled. Cross contamination of raw meat with other food items is also responsible for campylobacteriosis.

Raw and processed poultry products have been implicated as the major source of Campylobacter transmission to humans (Stern, N.J. and Robach, M.C., 1995). In order to eliminate the infection rate in humans it is necessary to reduce the frequency of Campylobacter in live birds and necessitate comprehensive control on the production facilities. Such controls can be implemented by identifying the sources/vectors responsible for Campylobacter incidences and establishing Critical Control Points. The objective of this study was to determine the frequency of Campylobacter from various preharvest sources with in a turkey production facility. 


\section{Material and Methods}

\section{Placement}

One flock was examined from February to March 2000. The flock was housed for a period of 21 weeks and poults were placed in the house at 2-3 days of age and removed 21 weeks later. The flock occupied 24 pens within the facility (Fig. 1) and was placed on fresh wood shavings as litter. Twelve pens on the northern end of the building were occupied by tom turkeys and the southern end of the building was occupied by hen turkeys. Samples were collected at weeks 18 and 21 of production.

\section{Collection and Transport}

Samples consisted of drinkers and fecal droppings. Throughout the study, all samples were collected in the same manner. Fecal droppings and drinker samples were collected twice throughout the last three weeks of the production period. During this collection process, 5 fecal droppings and 1 drinker sample was collected from each pen. Warm and moist fecal samples were collected in sterile Whirl-pak® bags (Fisher Scientific, Pittsburgh, PA), using sterile gloves and samples were placed on ice for transport. Sampling drinkers consisted of collecting $100-\mathrm{mL}$ of water from each drinker with a 50 $\mathrm{mL}$ pipette. These samples were stored in a $250-\mathrm{ml}$ sterile plastic bottle and placed on ice for transport. Samples were transported from the Reymann Memorial farm in Wardensville, WV to the West Virginia University Poultry lab in Morgantown, WV, and transport did not exceed $3.5 \mathrm{~h}$.

\section{Isolation and Conformation}

Fecal samples, $1 \mathrm{~g}$ was combined with $10 \mathrm{~mL}$ of NB \#2 (Appendix III) in a Whirlpak ${ }^{\circledR}$ bag (Fisher Scientific, Pittsburgh, PA). The sample was hand massaged for $30 \mathrm{~s}$, 
and a $0.1 \mathrm{~mL}$ sample was directly plated on a Campy-Cefex agar plate (Appendix II). For drinker samples, the sterile bottle containing the water was shaken vigourously to mix up contents, then a loopful of the water was streaked onto a Campy-Cefex agar plate. All agar plates were placed in a 3.79L zip-lock ${ }^{\circledR}$ bag. Each bag, contained 12 to 14 plates, the bags were flushed with microaerophilic air $\left(85 \% \mathrm{~N}_{2}, 10 \% \mathrm{CO}_{2}\right.$ and $\left.5 \% \mathrm{O}_{2}\right)$, sealed, and placed into an Imperial II incubator 422 (Labline Instruments, Inc., IL) for $36 \mathrm{~h}$ at $42^{\circ} \mathrm{C}$. After $36 \mathrm{~h}$, plates were examined for small, white, translucent colonies. Plates showing no characteristic colonies or no growth were discarded. Plates showing characteristic colonies were saved and a colony was picked and streaked to isolation onto a fresh Campy-Cefex agar plate. Once all plates were streaked to isolation, they were again placed into a 3.79L zip-lock ${ }^{\circledR}$ bag, flushed with microaerophilic air and returned to the Imperial II incubator 422 (Labline Instruments, Inc., IL) for an additional 24-h at $42^{\circ} \mathrm{C}$. After $24 \mathrm{~h}$, plates were again examined for characteristic small white translucent colonies. If plates had no growth, plates from the previous incubation period were used to streak for isolation again to confirm that the first transfer missed no bacteria. All plates showing characteristic colonies were confirmed as Campylobacter by selecting a single colony, in some cases 2-3 colonies, and using a campy latex agglutination test (Appendix IV) which is specific for C. jejuni, C. laridis and C. coli.

\section{Long-term Storage}

A single colony, from the same area of the plate that the colony for confirmation was selected, was transferred to a tube containing Protect beads (Appendix V). The tube was sealed and shaken 6 to 7 times and glycerol was aspirated off. All samples were stored at $-80^{\circ} \mathrm{C}$ until needed. 


\section{Results}

The overall frequency of Campylobacter was at $26 \%$ in this flock (Table 1). It declined from $31 \%$ at week 18 to $21 \%$ at week 21 . Campylobacter was detected more frequently in tom turkeys (40\%) than in hen turkeys (22.5\%). Campylobacter was not detected in water collected from drinkers. Fresh fecal samples accounted for $10 \%$ of all positive samples isolated. The frequency at which Campylobacter was isolated supports the implementation of on-farm practices to reduce levels of this organism in birds going to the processing facilities. 
Table 


\section{Samples collected from preliminary study}

Table 1. Prevalence of Campylobacter

\begin{tabular}{|c|c|c|c|c|c|c|}
\hline Sample & & & Grow & period & & \\
\hline & Wk 18 & & Wk 21 & & Total & \\
\hline Feces & $45 / 120$ & $37.50 \%$ & $30 / 120$ & $25 \%$ & $75 / 240$ & $31.30 \%$ \\
\hline Drinkers & $0 / 24$ & $0 \%$ & $0 / 24$ & $0 \%$ & $0 / 48$ & $0 \%$ \\
\hline Total & $45 / 144$ & $31.30 \%$ & $30 / 144$ & $20.80 \%$ & $75 / 288$ & $26 \%$ \\
\hline Fresh & $16 / 120$ & $13.30 \%$ & $8 / 120$ & $6.70 \%$ & $24 / 240$ & $10 \%$ \\
\hline Male & $31 / 60$ & $52 \%$ & $17 / 60$ & $28.30 \%$ & $48 / 120$ & $40 \%$ \\
\hline Female & $14 / 60$ & $23.30 \%$ & $13 / 60$ & $21.70 \%$ & $27 / 120$ & $22.50 \%$ \\
\hline
\end{tabular}




\section{CURRICULUM VITAE}

$\begin{array}{ll}\text { Parents } & \text { Melvin D. Kiess } \\ \text { Carla E. Kiess }\end{array}$

Birthplace Elkins, WV

Date of Birth January 27, 1976

Schools Attended West Virginia University

Degrees Conferred Master of Science in Animal and Veterinary Science 2001

Bachelor of Science in Animal and Veterinary Science 1999 